\title{
Una interpretación estructuralista de la "crisis" actual del capitalismo ${ }^{*}$
}

\author{
LA DIVISIÓN INTERNAGIONAL DEL TRABAJO Y LOS SISTEMAS \\ ECONÓMICOS NAGIONALES
}

Al observar el panorama ofrecido por la economía mundial a lo largo del siglo pasad.o, y en especial durante la segunda mitad de éste, se comprueba que las enormes transformaciones que tuvieron lugar se articulan en torno a dos hechos fundamentales: el primero de ellos se relaciona con la intensificación de la acumulación de capital en los procesos productivos y el segundo con el incremento, no menos considerable, del comercio internacional. Ambos procesos generaron incrementos sustanciales en la productividad del trabajo y dieron lugar a una corriente cada vez mayor de recursos que se utilizaron para fortalecer la acumulación y para financiar el aumento y la diversificación del consumo de importantes grupos de población. La forma en que fue apropiado el fruto de estos incrementos de la productividad y el destino que se les dio constituye el problema fundamental del estudio de la evolución del capitalismo industrial. Al parecer, no cabe mucha duda de que, al menos en una primera etapa, gran parte del incremento de la corriente de recursos se canalizó hacia Inglaterra, que procuraría implantar y consolidar un sistema de división internacional del trabajo. Financiando las inversiones en infraestructura con vistas a ampliar el comercio internacional, Inglaterra intensificó la concentración geográfica de la acumulación de capital en su propio beneficio, ya que las actividades industriales que realizaba eran las que más necesitaban de tal acumulación.

La oposición al proyecto inglés de ordenación de la economía mundial se dejó sentir muy pronto y adoptó la forma de un esfuerzo por consolidar los sistemas económicos nacionales de los países que constituirían el exclusivo club de economías desarrolladas de la época actual. La razón por la cual se produjo tal oposición es problema de la historia, sobre el cual puede discutirse indefinidamente. Basta señalar que en todas partes, el éxito de la oposición se vinculó con

* Los copyrights de este trabajo pertenecen conjuntamente al Third Wrorld Forum y a Estudios Internacionales. 
una centralización de las decisiones económicas mayor de la que había caracterizado el capitalismo industrial inglés en su etapa de consolidación. En algunos casos tal centralización se lograría a través del predominio del sistema bancario; en otros, el propio Estado asumiría la dirección coordinadora. Esta oposición conduciría a alianzas de clases - burguesía industrial, comercial y financiera, propietarios rurales, burocracia estatal y ocasionalmente fracciones de la clase trabajadora- en torno a un "proyecto nacional". Las incompatibilidades entre tales proyectos nacionales dejarian una profunda huella en la segunda etapa de evolución del capitalismo industrial.

Si se comparan las dos etapas mencionadas del desarrollo del capitalismo industrial se comprueba que en la primera de ellas el comercio internacional experimentó un crecimiento relativo mayor. En efecto, hasta ahora el período de expansión más acelerada del comercio internacional es el comprendido entre $1840 \mathrm{y} 1870^{1}$. Pese a que la segunda etapa comenzó a definirse en el decenio de los 70, hasta fines del siglo el valor del comercio internacional de productos manufacturados todavía aumentará con mayor rapidez que el conjunto de la producción industrial de los paises que participan en él. Sin embargo, el cambio de la tendencia ya se venía manifestando y durante toda la primera mitad de este siglo el desarrollo industrial se apoyó principalmente en los respectivos mercados internos. ${ }^{2}$

La inestabilidad intrínseca de las economías capitalistas industriales es un punto sobre el que están de acuerdo todos los estudiosos del tema. Hay amplias pruebas estadisticas de que tal inestabilidad tiende a adoptar la forma de fluctuaciones cíclicas en el plano de la actividad económica en general y del empleo en particular. De ahi que el desempleo cíclico se haya transformado progresivamente en preocupación central de las naciones de economía capitalista más avanzada. Sin embargo, la terapéutica contra tal inestabilidad vendría a fortalecer la tendencia a "cerrar" las economías nacionales. Pese a que desde la primera Guerra Mundial Inglaterra también se orientó al proteccionismo, su posición de centro financiero mundial la llevó a defender por todos los medios la posición internacional de la libra esterlina que a la sazón era la principal moneda de reserva. Lo más probable es que el estado de concentración económica relativa por que atravesó la economía inglesa durante los años veinte, cuando las demás economías industriales se expandían rápidamente, haya influido en la orientación del pensamiento de Keynes, que

2Véase A. H. Imlab, Economic Elements in the Pax Britannica (Cambridge, Mass., 1958), pág. 190, como asimismo A. G. Kenwood y A. L. Loughheed, The Growth of the International Economy $1820-1960$ (Londres, 1971), pág. 90.

"Véase A. Maizels, Industrial Growth and World Trade (Londres, 1963), págs. 139-140 y 388. 
Oelso Eurtado / Una interpretación estrucluralista de la "crisis" actual del capitalismo puso tanto énfasis en la necesidad de anteponer la estabilidad interna a la externa. Tal énfasis puede comprenderse tratándose de un país que en esa época pagaba de un cuarto a un tercio de sus importaciones con ingresos provenientes de capitales invertidos en el extranjero. En otras palabras, el hecho de que Inglaterra tratara de corregir un poco los excesos del internacionalismo no revestía gravedad. Sin embargo, aplicada a las demás economías industriales, la fórmula keynesiana fortalecería las tendencias estructurales de la segunda etapa del desarrollo del capitalismo industrial: Ios centros internos de decisión y coordinación ampliarían sus actividades y se pondrían a disposición de los gobiemos nacionales nuevos instrumentos de política. De otro lado, mantener un elevado nivel de empleo significaba aumentar considerablemente la corriente de recursos disponibles para inversión, Io que entrañaba incrementar el potencial de crecimiento. En realidad la fórmula keynesiana apuntaba hacia una amplia gama de opciones nuevas: necesidad de avanzar de manera progresiva, hacia la planificación y hacia una política de ingresos; necesidad de un control centralizado de las relaciones comerciales y financieras externas; necesidad de cambiar el estilo de desarrollo para hacer frente a la ampliación del potencial de crecimiento. Sin embargo, tales líneas de evolución contenidas implicitamente en el pensamiento keynesiano no llegaron a definirse. La agudización de los conflictos entre los "proyectos nacionales" provocaría nuevas modificaciones de fondo en la evolución del capitalismo industrial.

LAS CONSECUENCIAS DE LA SEGUNDA GUERRA MIUNDIAL

No es necesario ser muy perspicaz para darse cuenta de que el segundo conflicto mundial generó las condiciones para que el sistema capitalista Ilegase a funcionar con un mínimo de unidad de la autoridad política apoyado en un esquema unificado de seguridad. El hecho de que el mayor sacrificio humano y económico en el conflicto le haya correspondido a la Unión Soviética y que la destrucción del poder político-militar de Alemania y el Japón haya beneficiado casi exclusivamente a los Estados Unidos dentro del campo capitalista, son datos históricos que hay que aceptar como tales. Lo que interesa señalar es que, una vez establecida la tutela política estadounidense, se crearon las condiciones para que en el sistema capitalista se produjesen importantes modificaciones estructurales. Es posible que tal tutela política se haya aceptado más fácilmente por el hecho de que, 
en el plano económico, no estuvo vinculada a un proyecto definido en términos de los "intereses nacionales" estadounidenses sino que se presentó como un instrumento de defensa de la "civilización occidental". De hecho, las nuevas condiciones generales bajo esa tutela conducirían a una mayor homogeneidad de las naciones capitalistas industrializadas, reduciéndose la desigualdad entre los niveles de ingreso de la población de los Estados Unidos, de Europa Occidental y del Japón.

El rasgo más característico del capitalismo en su fase evolutiva actual reside en que prescinde de un Estado, nacional o multinacional, pretendiendo establecer criterios de interés general ordenadores del conjunto de la actividad económica. La doctrina que presidió la nueva ordenación es fundamentalmente una reconstitución de la ideología liberal inglesa que sirvió de justificación y punta cle lanza para implantar el antiguo sistema de división internacional del trabajo. Los acuerdos de Bretton Woods (1944) le asignaron al dólar funciones de moneda de reserva análogas a las que empezó a desempeñar la libra esterlina cuando más de la mitad de las exportaciones mundiales de manufacturas se originaban en los puertos ingleses. La Carta de La Habana y la creación del GATT (1948) definieron los fundamentos justificativos y los mecanismos operativos para asegurar la destrucción progresiva de las barreras al comercio entre las economías capitalistas. Contrariamente a lo que se piensa por lo general, la formación del Mercado Común Europeo no estuvo en desacuerdo con tal línea de evolución. De acuerdo con el espíritu del GATT, el desarme arancelario puede limitarse a una subregión (aunque en algunos casos ello exija medidas correctivas de aumento de los aranceles), esperándose que la subregión tienda a ampliarse. En el caso del Mercado Común Europeo (formado inicialmente por seis países) tal enfoque hacía esperar que la evolución tuviese lugar en el sentido de una expansión dentro de la propia Europa occidental y, posteriormente, en el de la formación de un espacio económico unificado en el Atlántico Norte.

Una vez establecido el principio básico de unificación creciente del espacio económico dentro del sistema capitalista, los estadounidenses pudieron prestar amplio y generoso apoyo a la reconstrucción de las antiguas economías rivales. Asimismo apoyaron con entusiasmo los distintos proyectos de uniones aduaneras, zonas de libre comercio y mercados comunes, conscientes de que se trataba de etapas en la destrucción de lo que restaba de los antiguos "proyectos nacionales". Un aspecto difícil del trabajo de limpieza del terreno que ocasionalmente provocaría fricciones fue la destrucción de las antiguas estructuras coloniales.

De esta manera, los sistemas nacionales, que son los marcos que 
Oelso Eurtado / Una interpretación estructuralista de la "crisis" actual del capitalismo

delimitaron la fase anterior del proceso de industrialización fueron perdiendo su perfil. Se produjo una situación similar a la prevaleciente cuando Inglaterra era el núcleo del sistema capitalista. Del mismo modo en que el antiguo empresario inglés, que financiaba su proyecto en la City, se consideraba libre para situar sus actividades en cualquier parte del mundo, las filiales internacionales de una empresa estadounidense o italiana que opera legalmente en Luxemburgo o en Suiza, también se sienten libres de iniciar o ampliar actividades en éste o aquel país, en función de sus propios objetivos de expansión. La diferencia con el antiguo modelo inglés reside en que el empresario individual fue sustituid:o por la gran empresa.

\section{LA COORDINAGIÓN OLIGOPÓLIGA Y FINANCIERA}

Aunque presenta semejanzas con la primera etapa de evolución del capitalismo industrial, hay que reconocer que los elementos fundamentales de la etapa actual (la gran empresa y las formas oligopólicas de mercado) se deben a la segunda. En efecto, la gran empresa exige un grado mucho más avanzado de coordinación de las actividades económicas que el que corresponde a los mercados tradicionales. La transición se consumó más fácilmente en los Estados Unidos donde un sistema económico nacional altamente protegido pudo crecer con extraordinaria rapidez a través de la incorporación de territorios y poblaciones. La tendencia inicial a la concentración horizontal, que en algunas ramas industriales dio lugar a situaciones de virtual monopolio, provocó fuertes reacciones encaminadas a resguardar el interés público, como las leyes anti-trust de fines del siglo pasado. Tendieron a prevalecer formas más flexibles de organización de las actividades económicas, como el oligopolio, en las cuales un grupo pequeño de grandes empresas se conjugan para levantar barreras al ingreso de otras en un sector de actividad económica y para manejar los precios de ciertos productos, eliminando el exceso de incertidumbre de los mercados tradicionales y reduciendo el margen de poder de los que "especulan" en tales mercados. Demás está decir que las empresas así articuladas conservan autonomía administrativa, financiera y tecnológica. La mayor estabilidad de precios genera ventajas relativas para las empresas que se sitúan a la vanguardia de la tecnología, sea en lo que toca a los procesos productivos, sea en lo que respecta a la introducción de productos nuevos. A diferencia de la competencia tradicional de los precios que debilita financieramente a las empresas, el mundo de los oligopolios estimula el 
crecimiento de todos los que participan en él; las fusiones ocasionales contribuyen a homogeneizar el grupo o a consolidar la posición de la empresa que lo lidera.

A primera vista podría parecer que la gran empresa deriva su poder de factores tecnológicos, como las economías de escala de producción. Esto es sólo parcialmente efectivo. Las economías de escala son fundamentales en las industrias de proceso continuo o cuando el trabajo puede organizarse en cadena. En el caso de la integración vertical, la ventaja principal deriva de que casi siempre reduce los costos de transporte y almacenamiento de los productos intermedios y muchas veces la carga tributaria. Además, en lo que toca a los productos intermedios la integración vertical reemplaza la incertidumbre del mercado por la planificación. Las empresas que surgieron de esta clase de integración fueron las primeras en adquirir y acumular experiencia en la organización de la producción a escala internacional.

Resulta fácil comprender, por ejemplo, por qué una firma que integra internacionalmente las distintas etapas de producción de un metal no ferroso llega a interesarse cada vez más en la utilización final de este metal. En algunos casos, se trata tan sólo de llevar más lejos el proceso de integración vertical, pero en muchos otros la empresa busca penetrar en nuevos sectores productivos en los cuales el metal no ferroso en cuestión es tan sólo uno de los insumos utilizados. El objetivo principal puede ser reducir la incertidumbre de los mercados. Sin embargo, no puede pasarse por alto el hecho de que por este medio la empresa aumenta su poder frente a otros sectores de la economía y a las autoridades públicas. Así, durante mucho tiempo las empresas norteamericanas que producían cobre en Chile aplicaron una política de precios del productor que les permitía vender el metal en condiciones mucho más favorables a otras empresas del mismo grupo. De esta manera lograban reducir la carga fiscal que recaía sobre ellas en Chile. En esta materia, la línea que sigue la empresa consiste en reducir el precio de producción (en especial los impuestos que a menudo representan más de la mitad de dicho precio), aumentar la flexibilidad internacional pudiendo transferir recursos de un país a otro, y reducir la incertidumbre para poder planificar su expansión a mayor plazo. El indicador más significativo del éxito que logran los que dirigen una gran empresa es Ia tasa de expansión de ésta, que generalmente se mide por la velocidad con que aumenta el valor real de sus ventas. La búsqueda de diversificación, característica de la gran empresa moderna, se explica por el deseo de reducir la inestabilidad y aumentar las posibilidades de crecimiento. De esta manera, a las empresas que producen cobre naturalmente les interesa el sector del aluminio, ya que toda innovación tecnológica importante que ocurra en este último puede refle- 
jarse en el mercado del primero. Si se integran los dos metales en un mismo oligopolio aumentan las posibilidades de planificar a largo plazo. Por iguales razones, a las grandes empresas petroleras les interesará controlar parte de la producción de carbón e ingresarán firmemente en el sector de la energía atómica.

Si se examinan en conjunto la integración y la diversificación se comprueba que las empresas que se expanden en esos dos sentidos (el grupo petrolero que integra la refinación con la producción de petróle:o y con la petroquímica y se diversifica hacia la energía atómica) tienden a llegar a controlar actividades económicas que aparentemente no tienen ninguna relación entre sí. A partir de cierto punto, las ventajas de la diversificación pasan a ser índole estrictamente financiera ya que el exceso de liquidez de un sector puede utilizarse en otro ocasionalmente más dinámico. Ahora bien, este tipo de coordinación puede lograrse a través de instituciones bancarias que tienen más facilidad para obtener informaciones en todos los sectores de la actividad económica y rápido acceso a los mercados financieros. Esa doble coordinación alcanzada a través de las estructuras oligopólicas y de las instituciones financieras es una característica fundamental del capitalismo en su etapa actual. A ella se debe, en buena medida, la intensificación del crecimiento de las economías capitalistas como asimismo, la considerable aceleración del proceso de concentración de capital.

\section{LA UNIFICACIÓN DEL ESPACIO ECONÓMICO}

Es evidente que en la evolución actual del sistema capitalista los tres procesos mencionados a) la fórmula keynesiana tendiente a asegurar el pleno empleo; b) la unificación del espacio económico en el centro del sistema capitalista, y c) el predominio de la gran empresa que permite acelerar la concentración de capital se relacionan entre sí. De esta manera, señalamos que la mantención del pleno empleo amplió el horizonte de opciones. En la medida en que los sistemas de dominio social pretendieron reproducir los patrones de distribución del ingreso social, se hizo necesario acelerar el proceso de acumulación. Ahora bien, la gran empresa es el instrumento adecuado para materializar esa acumulación más rápida. De otro lado, la apertura al exterior permite ampliar la base de recursos primarios (sin la cual la acumulación plantearía problemas de rendimientos decrecientes), maximizar las economías de escala (importante en el caso de las empresas situadas en los países medianos o pequeños) 
y acelerar la difusión de las innovaciones técnicas, lo que permite reducir el tiempo que se tarda en recuperar la inversión en investigación y desarrollo. El pleno empleo y la apertura hacia el exterior convergen en el sentido de intensificar el crecimiento y crean condiciones para fortalecer la posición de la gran empresa. Sin embargo, la apertura al exterior es lo que permite lograr un rápido crecimiento con un mínimo de tensiones estructurales, es decir, permite conciliar la aceleración de la acumulación con la reproducción de la estructura social tal como ella es. Considérese el caso extremo de un país como Suiza: si sus grandes empresas no crecieran todas hacia el exterior, pudiendo tener acceso a recursos básicos y mercados en otros países, habría que modificar el estilo de desarrollo suizo probablemente en un sentido incompatible con la conservación de las estructuras sociales actuales cuyas capas superiores derivan gran parte de su poder de ingresos obtenidos en el extranjero. Así, pues, parece includable que el factor más importante de la actual configuración del sistema capitalista es el proceso de unificación del espacio económico, es decir, el proceso de integración creciente de las antiguas economías nacionales.

En los dos decenios comprendidos entre 1950 y 1970 la tasa promedio de crecimiento anual de las economías capitalistas inclustrializadas fue $4,7 \%$ (en el segundo decenio alcanzó a $5,7 \%$ ), lo que significa una velocidad más de dos veces superior a la que acusaron tales países en el período anterior a 1950. En los dos decenios mencionados sus exportaciones aumentaron a una tasa anual promedio de $8,6 \%$ y en los años sesenta tal tasa se elevó a 10,1\%. En otras palabras, el comercio exterior crecía a una tasa prácticamente dos veces superior a la de expansión del producto interno. Cabría agregar que el comercio entre los países industrializados aumentó aún más rápidamente ya que en el período mencionado su participación en el intercambio externo total de tales países pasó de 60 a $77 \%{ }^{3}$

Con todo, estos datos no ponen de manifiesto los procesos de integración en toda su dimensión ya que el concepto mismo de economía nacional no tiene la significación que tenía en el pasado.

"Véase Comisión Económica para América Latina, Estudio Económico de América Latina, 1971, Vol. I, cuadro 2. El proceso de integración de las economias industrializadas capitalistas puede medirse de distintas maneras. En Francia, el Institut National de la Statistique et des Etudes Economiques publica dos indicadores al respecto. El primero de ellos señala la proporción que corresponde a las importaciones de productos industriales en la oferta interna (producción + importaciones - exportaciones de productos industriales) : tal participación aumentó de $17 \%$ en 1959 a $45 \%$ en 1974 . El otro indicador revela la relación entre el valor de las exportaciones de productos industriales $y$ la oferta interna mencionada: en el mismo periodo tal relación varió de 30 a $46 \%$. Véase Commissariat Général du Plan, Les indicateurs associés all $6^{\circ}$ plan, 1974, No 3. 
Dentro del espacio económico en vías de unificación, formado por el conjunto de países capitalistas, no resulta fácil delimitar el sistema económico estadouniclense. El hecho de que en el mundo capitalista hay una tutela política de los Estados Uniclos, consecuencia de la unidad del sistema de defensa, resulta evidente para cualquier observadort. Sin embargo, no puede afirmarse lo mismo respecto de la actividad económica. No se trata por ejemplo, de que el subsistema económico alemán sea relativamente más autónomo que el subsistema político alemán. La aparente mayor autonomía de Alemania Federal en el plano económico deriva, paradojalmente, del buen comportamiento de este país, que aplica con más severidad que cualquier otro las reglas del juego sancionadas por los Estados Unidos. De esta manera, el marco alemán fue revalorizado varias veces, al paso que el dólar se mantuvo durante más de diez años como moneda escasa sin que el gobierno de los Estados Unidos se sintiese obligado a cumplir las cláusulas del acuerclo de Bretton Woods que en tal caso contemplaban la revalorización. Si se hubiesen aplicado tales cláusulas, la capaciclad de expansión internacional de la economía estadounidense habría sido menor. Con todo, la verdad es que las fronteras de los antiguos sistemas económicos nacionales van desapareciendo sin que se haya definido con claridad la estructura del nuevo sistema global. Las grandes empresas, que reúnen creciente poder dentro de las nuevas estructuras, aún no poseen un estatuto clefinido. Los recursos líquidos o semilíquidos de que disponen estas grandes empresas, denominadas multinacionales son en la actualidad muy superiores a las reservas de todos los bancos centrales del mundo capitalista, particularmente si se tiene presente que las reservas de oro no son operativas. Los recursos que fluyen en el mercado financiero internacional y que escapan al control de cualquier autoridad monetaria, suman centenas de miles de millones de dólares. Hay por tanto una esfera de decisiones que no se confunde con los marcos institucionales controlados por los Estados nacionales. Todo ocurre como si hubiese surgido una nueva dimensión en el conjunto de las decisiones económicas que escapa a las formas institucionalizaclas de acción de los gobiernos en los planos nacional e internacional. En síntesis, dentro del marco institucional actual, los gobiernos no tienen posibilidades de coordinar las actividades que realiza todo un conjunto de poderosos agentes en el sistema capitalista. Si hay alguna coordinación, ella se da en el marco de los oligopolios y consorcios financieros, en los cuales la presencia

"La unidad de los sistemas de defensa de Europa Occidental y los Estados Unidos fue confirmada una vez más en la reciente "Declaración Atlántica", de 19 de junio de 1974. Véase Le Monde del 21 de junio de 1974, pág. 5. 
de los gobiernos se manifiesta a través de la presión que éstos ejercen sobre los agentes.

Una forma simplificada de concebir la nueva estructura del sistema capitalista consiste en partir de los antiguos sistemas nacionales e identificar en cada uno de ellos su dimensión internacional, es decir, las exportaciones y lo que producen en el extranjero las filiales o subsidiarias de las empresas cuya casa matriz se encuentra en el país analizado. Se trata tan sólo de simples aproximaciones, ya que puede suceder que la filial de una empresa alemana en el Brasil sea dirigida indirectamente desde los Estados Unidos a través del control financiero de la casa matriz. La empresa que exporta desde Alemania puede ser filial de una empresa norteamericana, etc. No obstante, la aproximación es válida y conviene limitarla al sector manufacturero. Entre 1957 y 1965 las exportaciones norteamericanas de manufacturas aumentaron 4,2 mil millones de dólares, las alemanas 8,4 mil millones y las japonesas 5,2 mil millones. En el mismo período, la producción de las subsicliarias japonesas aumentó 600 millones, la de las alemanas 1,4 mil millones y la de las americanas $24 \mathrm{mil}$ millones. Parece evidente que las condiciones creadas con vistas a integrar el mundo capitalista provocaron diversas reacciones en estos países. En Alemania y el Japón, la mano de obra, que en el período mencionado aún era relativamente barata, y la etapa de desarrollo que dejaba margen para sustanciales ventajas de las economías de escala de producción permitieron que se siguiese la línea tradicional de integración a través de la exportación. En los Estados Unidos, donde las grandes dimensiones del mercado interno habían permitido que las empresas industriales agotaran la posibilidad de economías de escala, y donde el costo relativo de la mano de obra era muy superior, las empresas se orientaron directamente a la descentralización internacional ${ }^{5}$. Sin embargo, la tendencia sería a reproducir el modelo estadounidense: en 1971 la producción de las empresas japonesas en el extranjero (todos los sectores) llegaría a 9 mil millones de dólares, lo que corresponde a $37,5 \%$ del valor de las exportaciones y la de las empresas alemanas alcanzaría a 14,6 mil millones, lo que corresponde a $37,4 \%$ del valor de las exportaciones. En el mismo año, el valor de la producción obtenida en el extranjero por las empresas que forman el conjunto de los países capitalistas inclustrializados llegó a 318 mil millones de clólares, de los cuales 172 mil millones corresponde a las empresas estadounidenses. Si se tiene en cuenta que en el mismo año el valor total de las exportaciones del conjunto de paises mencionados alcanzó a 133,7 mil millones se verá claramente

"Véase R. Rowthorn y S. Hymer, International Big Business 1957-1967 (Cambridge University Press, 1971), prigs, 61-74. 
Oelso Furtado / Una interpretación estructuralista de la "crisis" actual del capitalismo

que desde hace algún tiempo la principal forma de integración del sistema capitalista viene siendo la expansión internacional de las grandes empresas. ${ }^{6}$

LAS NUEVAS FORMAS DE INESTABILIDAD

Si se tienen presentes los cambios ocurridos en el sistema capitalista a partir de la Segunda Guerra Mundial se comprende sin dificultad que la inestabiliclad que se manifiesta actualmente guarda poca relación con la inestabilidad cíclica del pasado. La crisis cíclica clásica se originaba en una economía dominante y se propagaba internacionalmente, a partir de su foco inicial. Es conocido el desquiciamiento que se produjo en la economía de los Estados Unidos en los años veinte, cuando un gran aumento de la productividad se canalizó fundamentalmente hacia la ampliación del excedente cuya aplicación dio origen a una onda creciente de actividades especulativas. En esa época, el problema de fondo residía en la manifiesta deficiencia de los mecanismos de coordinación en el plano nacional. Para subsanar tal deficiencia surgió la fórmula keynesiana mencionada que se prolongaría ocasionalmente en "políticas de ingreso", planificación indicativa y otras formas de coordinación macroeconómica. La situación actual es diferente porque los focos de inestabilidad surgen de lo que llamamos nueva dimensión internacional del sistema capitalista. Como en los últimos diez años esta dimensión se ha desarrollado considerablemente sin que se haya avanzado gran cosa en el sentido de someterla a control, la formación de procesos desestabilizadores aumenta de manera alarmante.

Como siempre sucede, las instituciones nacen prematuramente o se crean cuando ya son indispensables. Las dos principales instituciones que ideó el gobiemo de los Estados Unidos inmediatamente clespués de la guerra para ordenar la nueva economía internacional resultaron una prematura y la otra frustrada. La primera de ellas, el Fondo Monetario Internacional, operó principalmente como instrumento de control, al servicio del gobierno de los Estados Unidos, de las políticas económicas y financieras de los demás países, en especial de los llamados países en desarrollo. La segunda, la Organización Internacional de Comercio, no llegó a crearse. Dada la lentitud con que se abren paso las ideas en un terreno tan conflictivo

'Véase Las corporaciones multinacionales en el desarrollo mundial (Naciones Unidas, 1973), cuadro 19. 
era natural que tales instituciones tendiesen a transformarse en simples instrumentos para articular las políticas de los gobiernos nacionales o para que un gobierno interviniese en otros. Ahora bien, como se dijo, la nueva dimensión internacional de la economía capitalista surgía principalmente fuera del control directo de los gobiernos. Sin embargo, hay que reconocer que tanto la acción del GATT (que es lo que perduró de la Organización Internacional del Comercio) como del FMI contribuyeron a crear la nueva dimensión internacional del capitalismo. No hay que subestimar el clesarme arancelario que resultó de la acción metódica del GATT ni el fortalecimiento de la posición internacional del dólar asegurado por el FMI. No obstante, ninguna de las dos instituciones estaba preparada para abordar el nuevo tipo de problemas que se manifestarían en la forma de una creciente inestabilidad en el plano internacional.

Por lo general, se pone énfasis en la inestabilidad internacional en su forma monetaria. Desde el momento en que la moneda y'a no es una mercancía que se produce como las demás sino un signo sin costo alguno, el control centralizado del poder de emisión pasa a ser condición sine qua non para que un sistema económico opere con un mínimo de estabilidad. De hecho, en la evolución de los sistemas capitalistas nacionales, la creación de los bancos centrales fue un hito decisivo. Poder crear medios de pago significa estar en condiciones de apropiarse en cualquier momento de una parte de la corriente de bienes y servicios que está a disposición de una colectividad. Ahora bien, una empresa tiene la posibilidad de modificar a corto plazo su estructura financiera, es decir, de transformar un activo menos líquido en otro más líquido lo que, para los fines prácticos, puede tener el mismo efecto que emitir papel moneda. La teoría monetaria tradicional pasaba por alto este hecho al afirmar que, a corto plazo, la "velocidad de circulación" de la moneda es constante. Sin embargo, tal corto plazo puede variar mucho cuando se mira, descle el punto de vista de los agregados nacionales o de los flujos de fondos de una empresa. La manipulación de sus activos a corto plazo mediante operaciones de adelantos o atrasos (leads and lags), le brincla a una gran empresa la posibilidad de aumentar a corto plazo su coeficiente de liquiclez. Si la empresa opera en el plano internacional tal posibilidad de crear liquidez adquiere una nueva dimensión, ya que le permite a la empresa realizar transferencias financieras internacionales escapando al control de las autoridades monetarias de los países en que opera. El hecho de que se utilice ese poder de especulación contra la moneda de uno u otro país es sólo un aspecto del problema. Lo que hay que señalar es el hecho de que existe tal poder y que entraña la posibilidad de que centros 
de decisión que escapan a los sistemas de coordinación actualmente existentes en el mundo capitalista manejen un inmenso volumen de recursos. El informe de la comisión estadounidense de aranceles señala que en 1970, el volumen de activos de corto plazo disponibles en la economía internacional alcanzaba a 268 mil millones de dólares cle los cuales 190 mil millones eran controlados por las llamadas empresas multinacionales. ${ }^{\top}$

Para comprender mejor este complejo problema conviene tener presente desde un comienzo que, mucho más que moneda de reserva o sustituto del oro, el dólar es una moneda vehículo, es decir, un. instrumento de las transacciones internacionales. El persistente déficit de cuenta corriente del balance de pagos de los Estados Unidos clebe considerarse en este contexto. En concliciones normales un déficit de esta naturaleza significaría simplemente la aceptación de una deuda a corto plazo por los bancos centrales de otros países. Lo normal sería consolidar la deuda o liquidar los activos estadounidenses en el extranjero, o ambas cosas a la vez, a semejanza de lo que hizo Inglaterra después de la última guerra. Tales medidas se acompañarían de la desvalorización del dólar o de políticas restrictivas internas de indole fiscal o monetaria (o ambas a la vez) o bien de las dos cosas, conforme a la fómula impuesta a muchos países por el FMI. Pero ocurre que esos clólares no se mantienen inactivos en los bancos centrales, como las reservas de oro. En parte los retienen las grandes empresas que los canalizan hacia el mercado financiero internacional. Aún más, los bancos centrales también canalizan parte de sus dólares hacia tal mercado, contentos de obtener tasas de interés dos o tres veces más altas que las que devengan los títulos del Tesoro estadounidense. De esta manera, un clólar que se utilizó para pagar una adquisición en Alemania y que se coloca en el mercado de eurodivisas puede prestarse para pagar otra adquisición en Italia. Surge así la posibiliclad de crear liquidez internacional a base de dólares que en realiclad no son otra cosa que la anotación contable cle una deuda de un banco estadounidense con un banco europeo. Esta nueva forma de liquidez se pone a disposición cle las grandes empresas cuya capacidad de acción internacional resulta así ampliada. Operando a través de filiales situadas en paises donde no hay control de cambio una empresa grande puede recurrir a esta nueva liquidez generada en el mercado financiero internacional para actuar en el lugar y en el momento que le convengan. Estrictamente hablando tales formas de liquidez no son sino simples compromisos asumidos por instituciones financieras que actúan en el plano inter-

TVéase W. A. P. Manser, The finantial role of multinational enterprises (Associated Business Programs, Casseles, Londres, 1973). 
nacional y valen en la medida del crédito de éstas. Sin embargo, como se expresan en dólares, se vinculan con esta divisa para los efectos de su conversión a cualquier otra. De esta manera para el funcionamiento de este mercado financiero es importante que el dólar sea una moneda de oferta permanentemente elástica en el plano internacional. Tal elasticidad la aseguran el papel de moneda de reserva y el aumento permanente de las reservas de dólares que mantienen los principales países. El hecho de que durante todo el decenio pasado los Estados Unidos pudieran acumular una enorme deuda' externa en condiciones financieras más favorables que aquéllas de los préstamos más generosos otorgados a los países en desarrollo se debió a que el dólar estaba cumpliendo funciones más amplias que las de simple moneda de reserva. El saldo en dólares sirvió de apoyo al nuevo sistema financiero internacional gracias a lo cual las grandes empresas pudieron actuar con mayor libertacl a escala munclial.

Cabe añadir que a partir cle los años sesenta surgió un nuevo factor que tendría importancia cada vez mayor para la estructuración de la nueva economía internacional, a saber, la apropiación de parte sustancial del excedente originado en la economía de petróleo por agentes (gobiernos de países de escasa población) que tenían escasa capacidad para absorber tales recursos. En una primera eta$\mathrm{pa}$, los saldos de estos agentes se ingresaron en dólares y libras esterlinas en bancos internacionales. Posteriormente se exigió una garantía de convertibilidad de la libra en dólar y finalmente esta moneda se sustituyó totalmente por el dólar. Todo sucedió como si un grupo importante de países estuviese acumulando un saldo positivo de balance de pagos en cuenta corriente y exigiese que los países deudores convirtieran de inmediato la deuda en dólares. De esta manera, estos últimos países se vieron en la necesidad de tener un saldo favorable en sus transacciones corrientes con los Estados Unidos o sea, se dio la posibilidad cle que este último se endeudase sin costo alguno. Los dólares del petróleo (u otros similares) se pondrían a disposición de las instituciones financieras que actúan independientemente de los sistemas de control de cambios y alimentarían los canales de liquidez que abastecen a las grandes empresas que operan en el plano internacional.

LA DIFUSIÓN DE LAS ONDAS DE INESTABILIDAD

Cuando se observa la economía internacional actual, en que no hay órganos de coordinación o control y donde hay un inmenso volumen de recursos de alta liquidez disponible para especulación, sorpren- 
de la relativa estabilidad del conjunto del sistema capitalista. La razón quizá se deba a que los instrumentos de control que operan en el plano nacional alcanzaron un alto perfeccionamiento, de tal modo que las ondas generales por turbulencias en la dimensión internacional se amortiguan al extenderse a las economías nacionales. Así, pues, la situación es contraria a la que existía en el ciclo clásico del sistema capitalista, cuando la perturbación se generaba en el interior de la economía dominante y encontrarba en la esfera internacional condiciones altamente favorables para difundirse. La reducción del nivel de actividad económica de los Estados Unidos, como la ocurrida entre 1929 y 1933, provocó una declinación más que proporcional de la demanda de importaciones y una baja aún mayor de los precios de los productos importados, particularmente de las materias primas. En la actualidad los principales focos de inestabilidad se forman en la dimensión internacional pero su difusión nacional es detenida por rigidices estructurales y corregida o compensada por la rápida acción de los gobiernos. En el caso de las bajas de precios de los productos importados la difusión interna es casi nula y se deja sentir lentamente; en todo caso, el efecto más probable será el aumento de la tasa de utilidad de ciertas actividades. En el caso de un alza importante de los precios de las importaciones se plantea el doble problema de la disminución directa del ingreso real disponible para el consumo (caso de los bienes de consumo importados que son objeto de reducida transformación) y del aumento de los costos de producción en los sectores que utilizan los productos en:cuestión. Por tanto; se trata de reducir el ingreso real de la colectividad, lo que en una economía de mercado no puede hacerse sin pasar por una o varias tentativas de modificar la distribución del ingreso. Ante todo hay que tener presente que la empresa moderna fija los precios de oferta incluyendo un margen de utilidad proporcional al costo básico de producción. De esta manera, el incremento del costo de producción provócado desde el exterior (elevación del precio de los productos intermedios importados) tiende a llevar envuelto un aumento de la utilidad con relación a los salarios; lo que entraña una primera tentativa de modificar la distribución del ingreso. Si el sistema económico fuese plástico, como les gusta suponer a los economistas, tal modificación en la distribución del ingreso tendería a estabilizarse ya que la primera disminución del poder adquisitivo de la pobalción entrañaría desempleo y éste llevaría a la masa trabajadora a aceptar una baja de los salarios. Ahora bien, tal plasticidad no existe: las estructuras económicas son, en realidad, una textura de relaciones sociales que reflejan un comportamiento conflictivo y no funcional. No es que ellas sean propiamente 
rígidas. No se puede desconocer que ofrecen diferentes grados de resistencia a una misma presión, según la manera en que ésta se ejerza.

En las sociedades capitalistas la única forma de reducir el poder comprador de la masa asalariada es permitir que se eleve el nivel general de precios o bien que se reduzca sensiblemente el nivel de empleo. En la medida en que se pretendió eliminar la segunda opción como instrumento de política, se tendió a aceptar la elevación ocasional del nivel general de precios como elemento inevitable si se pretende mantener las estructuras económicas con un mínimo de flexibilidad. Ahora bien, las mismas razones que hacen imposible la reducción de los salarios monetarios a corto plazo surgen para impedir que se reduzca el salario real a mediano plazo. En otras palabras, la reducción del salario real a corto plazo, derivada del alza de precios, provoca las reacciones que conducen a la elevación compensatoria del salario monetario a mediano plazo. Si el sistema se encuentra en expansión, entre el momento en que los salarios reales comienzan a bajar y aquel en que los salarios monetarios suben, para corregir esa baja, se elevará la productividad del trabajo, lo que introduce un nuevo factor de flexibilidad. La discusión en torno a la indización de los salarios (y de otras formas de ingreso), que se ha reavivado últimamente, parece desconocer que no se puede eliminar un elemento de flexibilidad del sistema económico sin introducir otro. En este caso, el otro elemento de flexibilidad sería, desde luego, la aceptación de un mayor margen de desempleo. Vincular la tasa media de salarios al indice general de precios puede ser también una forma de desvincular los incrementos de salarios de los aumentos de procluctividad del trabajo en el conjunto del sistema económico, y por tanto de provocar una concentración del ingreso. Esto no seria ni viable ni deseable en una economía industrial avanzada. La indización de los salarios y otras formas de ingreso se ha practicado, sin aumentar la rigidez del sistema, en países subdesarrollados donde sólo una parte de la población, está protegida por la legislación social. En este caso se mantiene la flexibilidad, pues cuando se elevan los precios y se defiende automáticamente el poder de compra de los asalariados (y el valor real de los activos financieros) crece la diferencia del nivè de ingreso real entre la minoría protegida por la legislación social y el resto de la población.

No se pretende afirmar que la inflación sea inherente a las economás capitalistas en estado avanzado de industrialización. Solamente se trata de reconocer que dichas economías encontraron en la inflación un medio de recuperar una flexibilidad estructural que la accion de otros factores tendía a reducir. Conciliar el pleno empleo 
con la estabiliclad exige la vigencia de un pacto social que regule el acceso a los frutos cle una rápida expansión del producto social. El fracaso de las llamadas políticas de ingreso ofrece una clara indicación de que en las sociedades en que la dinámica social se funda en conflictos entre actores que compiten por la distribución del ingreso y que son portadores de idleologías diversas, un pacto de esta naturaleza sólo adquiere consistencia en momentos históricos muy especiales. Lo anterior se puede observar claramente en Inglaterra, cuya sociedad siempre se catalogó como poseedora de una ejemplar disciplina social. La estabilidad tradicional de la economía inglesa se apoyaba en una masa crónica de clesempleo que se ampliaba en las bajas cíclicas. En todo el período comprendido entre las dos guerras mundiales, el coeficiente de desempleo se mantuvo alto en ese país, el primero en tomar plena conciencia del problema y en definir el pleno empleo como objetivo básico de la política económicosocial. En el famoso plan Beveridge, de 1942, se admitió que un coeficiente de desempleo de $7 \%$ de la fuerza laboral era socialmente aceptable. Ahora bien, la política cle pleno empleo, como ya observamos, aumenta el potencial de crecimiento y acumulación, y crea condiciones para avanzar mucho más de lo que habian sugerido los adeptos iniciales de la doctrina del pleno empleo. Tres decenios de política de pleno empleo produjeron una extraorclinaria cohesión en las organizaciones de obreros y asalariados en general. Frente a la creciente rigidez estructural del sistema, las grandes empresas inglesas buscaron invertir de preferencia en el extranjero. Así, lejos de producirse un pacto social en torno al objetivo del pleno empleo, surgieron nuevas formas de conflicto que no se tradujeron, como en el pasado, en un desempleo amplio, sino que provocaron el debilitamiento de las inversiones internas. $s$

Es cierto que la situación inglesa no se puede tomar como típica. Al ser la única, entre las económías capitalistas, que no se desarrolló a partir de un proyecto de sistema económico nacional sino de un proyecto de sistema de división internacional del trabajo, en el cual desempeñó el papel de núcleo dinámico, se comprende que la

${ }^{8}$ En la postguerra la tasa nedia de inversión de la cconomia inglesa fue del orden del $16 \%$, en tanto que en los países de Europa continental la tasa se situaba entre el 20 y el $30 \%$. Véase Erik Lundberg, Instability and Economic Growth, Yale University Press, 1968, pág. 151. En cambio, la expansión de lạs firmas industriales inglesas en el exterior fue considerable. Lfectivamente, en el periodo comprendido entre 1957 y 1965 el valor del incremento de las ventas de las subsidiarias $y$ filiales en el exterior de las firmas industríales inglesas alcanzó al $20 \%$ del total del incremento de las ventas de las empresas industriales inglesas dentro $y$ fuera del pais. La misma proporción fue de $13 \%$ en los Estados Unidos, $2 \%$ en. Alemania Federal y Japón, y $1 \%$ en Francia. Véase R. Rowthorn y S. Hymer, op. cil., pig. 62. 
economía inglesa encare dificultades particularmente grandes para conciliar el equilibrio interno y el externo, en el marco de una política de pleno empleo. Otras economías, como la francesa y la alemana, que habían conservado por más tiempo una parte relativamente importante de la fuerza laboral en la agricultura, mostraron mayor flexibilidad estructural en el marco de la política de pleno empleo. Tampoco hay que olvidar que debido a accidentes históricos (transferencias de población de Alemania Oriental a Alemania Occidental, y de Argelia a Francia) y a la afluencia de inmigrantes temporales, estos dos países se beneficiaron con una oferta más elástica de mano de obra. Lo que interesa señalar es que esas economías están marcadas por una vocación inflacionista, la que está alimentada por la inestabilidad externa. De esta forma los obstáculos que se oponen a una política de estabilidad interna no resultan sólo de la dificultad de conciliar el pleno empleo con la forma tradicional de distribución del ingreso; no menos importantes son las ondas crecientes de inestabilidad generadas en el exterior. Por tratarse de economías en que el valor de las transacciones comerciales externas (exportaciones más importaciones) corresponclen a más de $40 \%$ del ingreso nacional, la posibilidad de establecer amortiguadores, que impidan la propagación de las ondas desequilibradoras externas, es forzosamente pequeña. Más aún, esos amortiguadores vendrían a perturbar el proceso de unificación del espacio económico, factor esencial en la expansión de aquellas mismas economías.

LA ELEVACIÓN DEL PRECIO DEL PETRÓLEO

Es probable, por tanto, que la preocupación en torno a los focos de inestabilidad conduzca a una acción coordinadora de las actividades que llamamos de nueva dimensión internacional, entre las que se cuenta el manejo de un volumen creciente de títulos de créclito de elevado grado de liquidez, pertenecientes a agentes que no participan en los procesos productivos. Esta situación se vio agudizada por: la brusca elevación del precio del petróleo a fines de 1973. Todo ocurrió como si la tasa de ahorro planificada del conjunto del sistema capitalista hubiera aumentado bruscamente, lo que significa que la participación del consumo en el ingreso total debería disminuir de algún modo. Como el proceso de redistribución del ingreso entre paises y entre grupos sociales dentro de cada país se realiza con elevación del nivel de precios, el primer problema que surge 
Oelso Furtado / Una interpretación estructuralista de la "crisis" actual del capitalismo

es el de la reducción del valior real de un volumen considerable de títulos que circulan en el mercado financiero internacional. Se crearon, pues, las condiciones propicias para la especulación en torno a aquellas mercancias de circulación internacional y que pueden ser fácilmente almacenadas, ya que sirven de defensa contra la desvalorización de la moneda y de otros títulos financieros. Se transfieren dichas mercancías almacenadas, de manos de productores $y$ consumidores a las de especuladores, lo que inmediatamente repercute en el nivel de precios de los productos respectivos. En esta forma se origina toda una serie de ondas de inestabilidad contra cuya propagación se movilizaron los mecanismos de coordinación a nivel nacional. Dada la naturaleza conflictiva de las fuerzas que responden por la distribución del ingreso, la acción coordinadora tiende a asumir la forma de una reducción del nivel de actividad económica (de su tasa de expansión), o sea, de creación de desempleo. De persistir tales ondas de inestabilidad -que se transmiten de los mercados financieros a los de mercancías-, significa permitir que se ponga en peligro la política de pleno empleo a nivel nacional, cosa que no podrá dejar de agudizar los conflictos sociales. Ýa se nota una involución de este tipo en Inglaterra cuya economía es particularmente vulnerable a las ondas de inestabilidad originadas en la dimensión internacional, tanto por los motivos estructurales señalados, cuanto por el hecho de que la productividad del trabajo viene declinando en ese país en relación con las demás economías industriales avanzadas.

Si bien es cierto que Ias economías capitalistas son vulnerables a las ondas de inestabilidad generadas en la nueva dimensión internacional, también lo es que esa inestabilidad es de naturaleza distinta de la que acompañaba a las depresiones del pasado. Se puede percibir la diferencia fundamental entre los dos procesos si se tiene presente que actualmente el desempleo se está presentando concomitantemente con la elevación del nivel de precios. En la depresión clásica el desempleo era un proceso acumulativo que surgía de un cambio generalizado en la estructura de los activos de las empresas (liquidación de existencias) causado por una declinación previsible de la tasa de utilidades. Como el sistema de precios constituye un mecanismo de transmisión de informaciones, reacciona inmediatamente y anuncia la declinación del valor de todos los activos inmovilizados y la búsqueda de liquiclez. Todo ello se manifestaba en forma de una baja del nivel general de precios y de desempleo generalizado, el cual crecía en función de la resistencia que opusiera la estructura socioeconómica a la reducción de la tasa de salario monetario. La inestabilidad que actualmente se genera en la dimensión internacional no toma la forma de una contracción de la demanda 
sino la de fluctuaciones de precios derivados de movimientos especulativos o de una modificación en la relación de fuerzas entre grupos que se apropian del excedente creado en un país o en otro. Se trata, pues, de una inestabilidad que toma la forma de una modificación de las relaciones de intercambio. Consideremos el caso más importante, que es el de un brusco deterioro de las relaciones de intercambio de los países capitalistas industrializados, situación que se presentó recientemente como consecuencia del alza en los precios del petróleo y de otras materias primas. E1 problema fundamental que se plantea a los países afectados por la pérdida es el de distribuir entre distintos grupos sociales el efecto de la reducción de la productividad económica que viene aparejada con el deterioro de las relaciones de intercambio. Por un lado, se trata de reducir el gasto (los gastos de consumo o los de inversión, o ambas cosas), y, por otro, de reducir las importaciones o bien aumentar las exportaciones, o ambas cosas a la vez. Dichos ajustes toman tiempo y provocan diversas formas de fricción, y se hace necesario transferir recursos de unas actividades a otras, modificar planes de producción, etc. La repercusión a corto plazo, de estos ajustes en la productividad media del sistema es forzosamente negativa, lo cual complica aún más el problema de la repartición social de los efectos de la baja de la productividad venida del exterior. Es, pues, una tensión a nivel de la estructura del sistema, sin ninguna semejanza con las crisis de tipo tradicional. Como el alza de los costos de producción tiene un efecto inflacionario autónomo (aumento más que proporcional de los márgenes de utilidad) y como la ampliación de la oferta interna mediante importaciones queda descartada (precios en alza en el exterior y necesidad de volver a equilibrar el balance de pagos), la presión sobre la oferta interna tiende a aumentar acarreando una elevación del nivel de precios. Ahora bien, en una economía capitalista industrializada en situación de pleno empleo difícilmente se consigue reducir el nivel de consumo de la masa asalariada mediante una simple alza del nivel de precios. El riesgo de una espiral de precios y salarios, y el temor de un descenso de las inversiones, que generaría efectos acumulativos y provocaría una depresión de corte clásico, concluce a los gobiernos a tomar medidas de contención en el plano monetario y fiscal (sumadas a algunas formas de control de precios), de las cuales resulta la reducción del nivel de empleo. En este caso el desempleo se debe entender como un instrumento de política económica, mediante el cual se obtiene la reducción del consumo (anulando en parte la presión social que resulta del alza en el nivel de precios), reducción que no se puede obtener por medios inflacionarios, ni mediante una política de ingresos apoyada en un pacto social. Como instrumento de política, el desempleo está 
s.ometido a control. Si es posible admitir que un nivel de desempleo que se hubiera considerado alto hace algunos años tiende a hacerse crónico en las economías capitalistas avanzadas, no existe base para suponer que ese desempleo pueda escapar al control y tomar la forma de un proceso acumulativo similar al del ciclo clásico. ${ }^{\ominus}$

"Las tensiones o dislocaciones que ocurren actualmente en el sistema capitalista podrían ser interpretadas, en ciertos aspectos, como "crisis de crecimiento", pues todo sucede como si hubiera que reducir (por algún tiempo) el ritmo de crecimiento del consumo, con el fin de liberar recursos para intensificar las inversiones en la periferia (más exactamente: en aquellos sectores de ésta que se benefician con el mejoramiento de las relaciones de intercambio) y en el frente tecnológico: nuevas fuentes de energía, exploración del fondo del mar, etc. Pero no se debe deducir de ello que tales tensiones no entrañen riesgos de rupturas de consecuencias imprevisibles en el plano social. Dos situaciones parecen ser particularmente delicadas en la situación actual. La primera se refiere a Inglaterra, donde convergen actualmente un bajo nivel de eficacia de los centros de decisión, coordinadores de las actividades económicas con un máximo de fragilidad del sistema económico. La insuficiencia de las inversiones hechas en los últimos yeinte años se traduce ahora en un bajo nivel de competitividad de la industria inglesa en el plano internacional, situación que se extendió al propio mercado interno inglés por el tardío ingreso del país al Mercado Común Europeo. La otra situación delicada se relaciona con la vulnerabilidad de la situación financiera del conjunto de las empreșas norteamericanas.

La facilidad de endeudamiento externo que disfrutaron los Estados Unidos en los últimos diez años y la perspectiva de una inflación continua crearon las condiciones para que las empresas de ese país iniciaran un proceso de endeudamiento creciente; paralelamente, se modificaba la estructura financiera de esas empresas y aumentaba de modo considerable el endeudamiento a corto plazo. La relación entre utilidades (sin deducir los impuestos) más intereses e intereses por pagar, que en 1964 era de $1.200 \%$, en 1973 se habia reducido a $300 \%$; la relación entre activos líquidos y deudas a corto plazo, que era de $110 \%$, se redujo a $50 \%$ (Véase Business Week, 12 de octubre de 1974). Estos son promedios, que encubren la situación mucho más grave de numerosas empresas, algunas de ellas, entre las mayores del país. No cabe duda de que se trata de dos problemas distintos, pues la situación inglesa es estructural, y por tanto de corrección lenta. No obstante, si bien el problema nortcamericano es financiero, su solución resulta difícil por la vulnerabilidad de la situación de balance de pagos del país. En la situación actual, toda política expansionista en los Estados Unidos (aun partiendo de una situación de desempleo acentuado) tiene repercusiones inflacionistas internacionales, las cuales retroactúan a su vez sobre la economía norteamericana. Cabe reconocer, sin embargo, que el gobierno de los Estados Unidos dispone de medios para actuar en caso de agravarse la situación financiera de muchas empresas. No se puede decir lo mismo respecto del gobierno británico. Lo que importa recordar es que una agravación de la situación económica inglesa traeria repercusiones internacionales limitadas, o que sería posible controlar; si la agravación ocurre en los Estados Unidos, el sistema capitalista difícilmente podrá escapar a una crisis de proporciones mayores y consecuencias imprevisibles. 
LAS DISPARIDADES EN EL PROGESO DE AGUMUULAGIÓN

Hicimos referencia al hecho de que durante el último tercio del siglo pasado el núcleo industrial del sistema capitalista experimentó una ampliación importante de la cual derivaron modificaciones estructurales significativas. En muchos casos la preocupación por las economías externas dinámicas (a nivel de cada sistema nacional) se impuso al antiguo criterio de las ventajas comparativas, y la industrialización pasó a apoyarse de preferencia en los mercados internos respectivos, al tiempo que se reducía la tasa de expansión del comercio internacional. Las razones por las cuales tal o cual país adoptó o no esa línea de política pertenecen a la historia y no pueden tener su explicación en ninguna fórmula sencilla. Que la haya adoptado Italia y no España, el imperio zarista y no el turco, Japón y no China, son hechos de implicaciones geopolíticas considerables que moldear:on la historia del siglo actual. Efectivamente, los países que no experimentaron esa mutación política, es decir, aquellos en que no se presentaron o no fueron creadas las condiciones para que se siguiera de manera consecuente una política de integración nacional durante el período mencionado, permanecerán en una situación de dependencia que condicionará su evolución económica subsiguiente.

Para percibir el fondo de este problema conviene tener en mente que la evolución de la economía industrial se presenta en forma de dos corrientes de innovaciones: una de técnicas productivas y otra de bienes finales de consumo, las que se apoyan conjuntamente en el proceso de acumulación de capital. Si bien se trata en realidad de dos aspectos de un mismo proceso, las dos corrientes pueden ser objeto de transacción comercial separadamente. Así, se pueden adquirir en el mercadio nuevas técnicas productivas y utilizarlas para modificar bruscamente la estructura productiva de una región determinada. Por otra parte, se pueden adquirir los nuevos productos separadamente de las técnicas que se necesitan para producirlos, y utilizarlos para modificar la forma de vida de una población. A medida que avanza el proceso de industrialización, más complejas se tornan las técnicas productivas y más variada y abundante la corriente de bienes finales de consumo, mientras se eleva paralelamente el nivel de acumulación de capital, es decir, la dotación de capital por trabajador. En esta forma el trasplante de nuevas técnicas no se realiza sin reajustes estructurales entre países que dispo- 
nen de niveles de acumulación muy distintos, en tanto que la transferencia de nuevos bienes finales de consumo es tarea simple.

La estructura actual del sistema capitalista, por lo tanto, es en gran parte un reflejo de las disparidades geográficas en el proceso de acumulación de capital. La mutación que ya mencionamos significó optar por formas de crecimiento económico que permitían maximizar la acumulación a nivel del subsistema nacional. En aquellos países en que surgió una economía de enclave, de tipo agrícola o minero, no se presentaron ambigüedades, pues la corriente de utilidades era controlada desde el exterior. La rentabilidad de la firma que controlaba el enclave prevalecía sobre cualquiera otra consideración, y para ella era indiferente que sus inversiones crearan o no economias externas en el pais en cuestión. Si de tales inversiones resultaban modificaciones estructurales capaces de provocar una elevación de los costos de producción (elevación de la tasa de salario, por ejemplo) es natural que la firma afectada tratase de reducirlos y de desviar hacia otros países los recursos disponibles, incluso las reservas de depreciación. No obstante, el sistema de enclave no constituyó el factor determinante principal de las disparidades entre países respecto al proceso de acumulación. La especialización geográfica inherente a las ventajas comparativas significaba que muchas regiones podían tener acceso a aumentos de productividad económica mediante el empleo extensivo de recursos primarios, particularmente tierras cultivables. Todo ocurría como si existiese un potencial productivo disponible, cuyo aprovechamiento se tornaba posible con una ampliación del mexcad:o. Se creó así un excedente económico que pudo ser considerable, pues la reproducción de la fuerza de trabajo continuaba realizándose en el marco de la economía de subsistencia preexistente. Dicho excedente fue apropiado por una minoría (propietarios de tierras, comerciantes, intermediarios financieros, burócratas, etc.) y tomó la forma cle poder comprador en el exterior. El proceso de acumulación relativamente tardío (y de asimilación del progreso técnico en los procesos productivos) derivó de que ese poder de compra adicional fue utilizado fundamentalmente para financiar la difusión del flujo de innovaciones en el plano de Ios bienes de consumo. La apropiación por grupos locales del excedente produciclo por la inserción en el sistema de división internacional del trabajo, abría evidentemente una opción, que no existió para los países sometidos a la tutela colonial y aquéllos en que prevaleció una economía de enclave. Con todo, en la casi totalidad de los casos prevalecieron las fuerzas que operaban en el sentido de vincular la utilización del excedente a un proceso de rápida modernización del estilo de vida de una minoría. Sería erróneo suponer que esta última opción era incompatible con el crecimiento econó- 
mico: en muchos países ella permitió incorporar recursos importantes al sistema productivo elevándose la productividad económica durante períodos prolongados. Lo que interesa señalar es que dicho crecimiento se hacía con un mínimo de asimilación de nuevas técnicas productivas. Incluso cuanclo no se apoyaba en la utilización de recursos no renovables o en la destrucción irreparable de los suelos (lo que solía ocurrir) reflejaba la incorporación de recursos en un marco tecnológico tradicional. En esta forma, mientras los bienes importados que se consumían incorporaban técnicas cada vez más complejas (y requerían para ser producidos una creciente acumulación en los países que los exportaban), la producción interna destinada a la exportación (que originaba el excedente) crecía horizontalmente, exigiendo un esfuerzo modesto de acumulación.

Las consecuencias del proceso de acumulación relativamente tardío son fáciles de percibir. Como la industrialización de un país, sea cual sea la época en que se realiza, se moldea por el grado de acumulación alcanzaclo en los países que van a la vanguardia del progreso técnico, el esfuerzo necesario para dar los primeros pasos tiencle a crecer con el tiempo. Por lo tanto, se comprende que a partir de cierto punto la posibilidad de optar por un proyecto de sistema económico nacional se haya tornado prácticamente nula. Es a partir de ese momento que se puede hablar de una diferencia cualitativa entre capitalismo céntrico y capitalismo periférico. El capitalismo céntrico comprende toda una constelación de subsistemas que presentan dispariclades considerables: hay países grandes y dominantes, como los Estados Unidos, pequeños con autonomía considerable como Suiza y Suecia, y grandes y dependientes como el Canadá. Pero desde el siglo pasado el crecimiento económico se basó en todos en una fuerte acumulación de capital, lo que significa que descle esa época buscaron el camino de la industrialización y/o de una gran tecnificación de la agricultura, sin lo cual no habrían alcanzado la considerable homogeneidad tecnológica que los caracteriza actualmente. El capitalismo periférico comprende disparidades aún mayores. Pero todos sus miembros tienen en común ciertos rasgos estructurales que provienen del hecho de que pasaron por un proceso de modernización de las formas de consumo de una parte de la población antes de adentrarse decididamente en el proceso de industrialización. En consecuencia, no se trata tanto de un problema de nivel de desarrollo como de diferencias cualitativas en el proceso de desarrollo. 


\section{LA INDUSTRIALIZACIÓN PERIFÉRICA}

La industrialización tardía ocurricla clentro del marco del capitalismo periférico no se orientó, en sus comienzos, en el sentido de formar un sistema económico nacional sino en el de robustecer la integración en el sistema de división internacional clel trabajo. Surgieron algunas industrias como una prolongación de las actividades exportacloras, con el fin de aumentar el valor agregado por la actividad primaria. Rara vez esas industrias creaban economías externas que viniesen a beneficiar a otras actividades productivas dentro del país. Otro conjunto de inclustrias surgió vinculado directamente a las importaciones, es decir, como una forma de aumentar el valor de las ventas del sector importador. Dado que la capacidad de importar operaba como variable independiente y establecía el tope para el volumen de negocios del sector importador, el camino que tenía éste para ampliar sus entradas era diversificarse en actividades manufactureras internas complementarias de las importaciones. Asi, importar hilo para producir tejiclos significaba un mayor volumen de negocios que importar tejidos. Este segundo tipo de industrialización fue estimulaclo por la inestabilidad de la capacidad para importar. En América Latina la depresión de los años 30 la incentivó considerablemente, dando origen al llamado modelo de industrialización sustitutiva de importaciones. Resulta fácil comprender que este tipo de industrialización tiende a robustecer la estructura social preexistente, basada en la apropiación por una minoría del excedente derivado de la especialización internacional y en la reproducción de la mano de obra dentro del marco de una economía de subsistencia.

Ya observamos que la característica fundamental del capitalismo periférico, al menos en su fase inicial, consiste en una asimetría entre la asimilación clel proceso técnico (el flujo de innovaciones) en el plano de los bienes finales cle consumo (importados) y en el plano de los procesos productivos. Dicha asimetría se manifiesta en la acumulación tardía vinculada clirectamente al proceso productivo, en relación con la acumulación implícita en el estilo de vida y, sobre todo, en los bienes importados que se consumen. Por ello, la urbanización trajo consigo formas de consumo que exigen una capitalización elevada: medios de transporte colectivo y privado, infraestructura de comunicaciones, servicios hospitalarios, culturales, etc. En otras palabras, la adopción del estilo de vida de los países industria- 
lizadios, incluso por una minoría reducida, exige una capitalización creciente directamente a nivel del consumo colectivo y privado. En síntesis, cuando se importan bienes de consumo corriente, la capitalización necesaria se realiza en el país productor de dichos bienes. Cuando se importan bienes de consumo durable (automóviles particulares, aparatos electrodomésticos, etc.) la capitalización se realiza simultáneamente en el país productor y en el país importador, pero en este último caso a nivel de los agentes que consumen esos bienes. En los países de capitalismo céntrico esa capitalización improductiva se presenta concomitantemente con la elevación de la productividad industrial. En efecto, los recursos necesarios para financiar la venta de los bienes de consumo durable provienen del aumento de la productividad del propio sector industrial. En un país de capitalismo periférico, que importa los bienes mencionados, el esfuerzo de capitalización improductiva exige una mayor concentración del ingreso, sea mediante la ampliación relativa del excedente, sea mediante la reducción del número relativo de los que se benefician de ese excedente. En consecuencia, el aumento de la tasa de ahorro no significa necesariamente aumento de la capacidad de inversión en el sistema productivo.

Por lo tanto, en un país de capitalismo periférico existen tendencias estructurales en el sentido de concentración del ingreso y de orientación del ahorro hacia inversiones improductivas. Tales tendencias contribuyen a tornar aún más escasos los recursos disponibles para la industrialización, escasez que se agrava con el tiempo, ya que el proceso de substitución de importaciones avanza por una rampa cuya pendiente mide la intensidad de capitalización por unidad de ingreso. Para comprender mejor este problema conviene tener en cuenta que en el capitalismo periférico la industrialización se apoya en dos mercados de dinámicas muy diversas. El hecho de que la reproducción de gran parte de la fuerza de trabajo se realice dentro del marco de la economía de subsistencia hace que la tasa de remuneraciones de los trabajadores no calificados tienda a ser estable. El mercado formado por esta parte de la población está en permanente expansión, sea porque la población aumenta, sea porque está creciendo la proporción de trabajadores urbanos no calificados incluidos en esa masa cuya remuneración es mucho mayor que la del trabajador rural. Sin embargo, se trata de un crecimiento que casi no implica diversificación de la demanda o introducción de nuevos productos. La sustitución de importaciones en este sector se realiza con rapidez pero con una tasa de crecimiento decreciente, tasa que se estabiliza a un nivel modesto. El otro mercado tiene como núcleo principal a la minoría que se apropia del excedente, pero incluye además a los cuadros profesionales y burocráticos supe- 
riores e incluso los operarios mejor calificados. Como se ha formado bajo la influencia de las importaciones, este mercado constituye un foco de irradiación de los valores culturales del capitalismo céntrico. Por el hecho mismo de que la tasa de remuneraciones tiende a ser constante, los incrementos de la productividad (cualquiera que sea su origen) benefician esencialmente a este segundo mercado. Como la industrialización significa aumento de la productividad, ella también contribuye a dinamizar este mercado. Así, para que la sustitución de importaciones pueda avanzar realmente deberá basarse en este sector dinámico del mercado.

La discontinuidad clel mercado de manufacturas que acabamos de mencionar constituye una de las características fundamentales del capitalismo periférico. Ya señalamos que la intensidad de la capitalización no es independiente de la naturaleza del mercado, es decir, del nivel de ingreso de los consumidores y del grado correspondiente de diversificación de la demanda. El paso de la industrialización del primer segmento del mercado al segundo segmento corresponcle a un verdadero salto en la intensidad del esfuerzo de capitalización. Es verdad que la capitalización correspondiente al segundo segmento se realiza parcialmente a nivel del consumidor que adquiere los bienes durables, y esa parte de la capitalización se inicia con anterioridad a la formación del mercado alimentado por las importaciones. Pese a ello el esfuerzo adicional tendrá que ser considerable, ya que se trata ahora de completar la estructura industrial mediante la instalación de industrias intermediarias que generan las economías externas, sin las cuales las industrias de bienes de consumo durable no serian viables. Es preciso agregar que este nuevo bloque industrial se apoya esencialmente en las economías de escala, lo que significa que el esfuerzo de capitalización es relativamente mayor en la fase inicial.

LA APROPIAGIÓN DEL EXCEDENTE EN LA PERIFERIA

La intensidad de la acumulación en el capitalismo céntrico, va acompañada por la elevación de la productividad promedio, el nivel promedio de ingreso y la capacidad promedio de ahorro. En el capitalismo periférico, en vista de la discontinuidad mencionada, la industrialización sólo puede proseguir si hay una fuerte afluencia de recursos externos y/o una mayor concentración del ingreso. Las dos formas de movilización de recursos han sido utilizadas por la totalidad de los paises de capitalismo periférico en la fase de intensificación de 
la industrialización. Una vez acelerado el proceso de industrialización, el excedente tiende a ampliarse en términos relativos, es decir, se intensifica la concentración del ingreso puesto que la productividad aumenta con intensidad mientras la tasa de remuneraciones permanece estable. Con todo, las necesidades de capital también están aumentando, ya que el sistema industrial va adquiriendo dimensiones y subiendo la pendiente ya descrita. En esta fase las actividades industriales de los países de capitalismo periférico tienden a ser controladas por grandes empresas de acción internacional. La escasez interna de recursos sirvió en muchos países de justificación para ofrecer ventajas adicionales a esas empresas, las que tendieron a ocupar los sectores en que el control de la tecnología proporcionaba mayores ventajas. Ubicadas en posiciones estratégicas están en condiciones de apropiarse de una parte creciente del excedente en expansión que mencionamos. Así se explica que la mutación del proceso de industrialización haya ido acompañada en general por otra mutación del sistema de control de la actividad industrial, en que la clase capitalista local ha sido sustituida rápidamente por representantes de grandes empresas de acción internacional.

La evolución del capitalismo periférico se manifiesta, necesariamente, en el plano de las estructuras internas de dominación. EI sistema de división internacional del trabajo creó en los países exportadores de materias primas burguesías dependientes, que actuaban como focos irradiadores de los valores culturales generales en los países céntricos. Así se produjo la dominación cultural dentro de la cual se moldearían las estructuras económicosociales. Sería ingenuo sustituir la compleja realidad histórica por un estereotipo, a semejanza de los teóricos de la burguesía compradora. La preexistencia o no de un estado estructurado que ejercía una soberanía relativa constituyó siempre un factor de peso. La naturaleza de la actividad exportadora influyó también decisivamente en el moldeamiento de dicha burguesía. Ya mencionamos la especificidad de aquellas economías en que el sector exportador asumió la forma de un enclave controlado desde el exterior. Fue en los países con enclave minero donde primero se configuró una relativa autonomía del estado, el cual tendió a asumir el papel de "representante del interés nacional" como interlocutor de los grupos controladores de la actividad exportadora. La apropiación por el estado de parte del excedente generado en el sector exportador contribuirá a que surja y se: amplíe un núcleo tecnoburocrático que en muchas oportunidades asumirá el verdaclero papel de árbitro en la estructura de poder. No deja de ser significativo que en todos los países latinoamericanos de capitalismo periférico en que se realizó una importante reforma 
Oelso Furtado / Una interpretación estzucturalista de la "crisis" actual del capitalismo

agraria -México, Bolivia, Perú y Chile- el sector exportador fue originalmente un enclave minero.

La forma como la burguesía en un comienzo dependiente se transformó en burguesía industrial, tampoco puede ser explicada fácilmente. Allí donde el primer núcleo industrial estuvo integrado principalmente con las exportaciones, como fue el caso de Argentina, la solidaridad de los dos grupos (exportadores e industriales) fue más consistente y duradera. Cuando el primer núcleo industrial estuvo ligado principalmente a las importaciones, que complementaba o pretendía sustituir, como fue el caso del Brasil, los intereses del grupo industrial y del grupo exportador no siempre pudieron armonizarse. En este segundo caso cabe hablar del germen de una burguesía nacional en el sentido europeo, o sea, un grupo dominante que se presenta como defensor de los "intereses nacionales", afianzándose frente a los demás grupos dominantes, estén estos vinculados o no a los intereses externos. Es posible que el grupo industrial brasilero no haya asumido efectivamente el papel de burguesía nacional y controlado el estado debiclo al éxito que tuvo la política de valorización del café en el primer decenio de este siglo10. En todo caso, los ensayos realizados en los años 30 serían tardíos, puesto que los cambios estructurales que ocurririan en el sistema capitalista en el decenio siguiente conducirían a un rápido control de las actividades industriales brasileras por empresas de acción internacional. Esto no impidió que el grupo industrial local continuase creciendo y aumentando su influencia sobre el estado. Lo que interesa señalar es que ese crecimiento se haría dentro del marco de una creciente integración tecnológica, financiera y administrativa con empresas de acción multinacional, lo que otorgaría a la industrialización brasileña, y periférica en general, el carácter de prolongación de los sistemas industriales de los países céntricos.

Cabe destacar que la intervinculación con las empresas de acción internacional no impide que la clase industrial local posea una óptica distinta de la que era propia de los grupos dominantes vinculados a la exportación de productos primarios. En efecto, aunque la industrialización periférica tiencla a excluir de sus beneficios a la masa de la población, no por eso deja cle apoyarse en el mercado interno, el que debe ser defendido y ampliado, si es necesario, me-

${ }^{10} \mathrm{~L}$ a valorización del café consistió en una política de retención de existencias $y$ de ordenación de la oferta en cl mercado internacional, lo que fue posible debido al hecho de que el Brasil contribuia con dos tercios de esa oferta. Dicha política, que permitió reducir el margen de poder de los especuladores, debe ser considerada como pionera en los esfuerzos que realizan actualmente los países subdesarrollados para mejorar sus relaciones de intercambio. Véase C. Furtado, Formação económica do brasil, primera edición de 1959, 12a edición, 1972, cap. XXX. 
diante reformas estructurales compatibles con un tipo de acumulación que exige la concentración del ingreso. Así se explica que en muchos países se realicen reformas agrarias tendientes a eliminar "estructuras anacrónicas", a ampliar los mercados, etc. Esas reformas han contribuido a dar más homogeneidad al grupo dominanté y a robustecer el sector de la agricultura más apto para crear un excedente comercializable. Ahora bien, resulta significativo que las reformas agrarias (así lo demuestra la experiencia latinoamericana) no hayan modificado la tendencia a la concentración del ingreso. Dentro del marco del capitalismo periférico, esa concentración amplía el mercado-interno, siendo un requisito para que prosiga la industrialización. Ptor otro lado, la necesidad de intensificar el esfuerzo de capitalización exige una acción más amplia del estado. En muchos países el poder público se transformó no sólo en fuente principal de financiamiento sino también en agente económico que asumiría la carga de las inversiones a largo plazo en infraestructura.

Así, la ascendencia de los intereses industriales dentro de la clase dominante se produjo paralelamente a la ampliación de la acción del estado como agente económico. Siendo el principal instrumento de captación de recursos financieros, controlando directamente empresas de gran envergadura, asociándose a grupos internacionales, ejerciendo el poder regulador, pretendiendo ser el único intérprete del interés público en sociedades en que la mayoría de la población no está representada en el sistema político, el estado que fue emergiendo en los países de capitalismo periférico en la fase de industrialización es una institución en cierto modo sui generis. Sus responsabilidades directas en el plano éconómico son mucho mayores de las que experimentó hasta ahora el estado del capitalismo céntrico. La especificidad de ese poder deriva no tanto del desempeño de funciones burocráticas tradicionales como de funciones tecnoburocráticas similares a las que en el capitalismo céntrico ejercen las grandes empresas. La preeminencia del grupo tecnoburocrático en las estructuras de poder constituye uno de los rasgos más característicos del capitalismo periférico contemporáneo. Como ya señalamos allí donde el sector exportador tradicional asumió la forma de enclave; la evolución en esa dirección fúe más rápida. Pero, en todas partes la industrialización está produciendo resultados similares. Todo induce a creer que el capitalismo periférico en su fase actual exige una mayor concentración de poder y mayor interdependencia entre lo político y lo económico de lo que fue la regla en la evolución del capitalismo céntrico. En efecto, si se tiene presente que la evolución del capitalismo periférico se hace mediante la asimilación de las pautas de consumo generadas en sociedades que se encuentran a un nivel de acumulación mucho más avanzado (lo que engendra 
una agravación de las clesigualdacles sociales inherentes al capitalismo), se entiende que surja con tanta frecuencia el estado autoritario en el mundo periférico. Por un lado, el proceso de acumulación requiere más a menudo modificaciones estructurales, muchas de las cuales tienen como objetivo confeso $u$ oculto facilitar la concentración del ingreso. Por otro, las crecientes desigualdades entre los niveles de consumo personal genera un incómodo potencial de inestabilidad social.

Si bien el surgimiento de un núcleo de poder tecnoburocrático es general en los países de capitalismo periférico, sería erróneo suponer que en todas partes dicho núcleo asume las mismas funciones. Hay casos en que el poder tecnoburocrático se coloca al servicio de los grupos internacionales, otros en que su principal objetivo es captar una mayor parte del excedente de que se apropian esos grupos en el país. Interesa destacar, que en la periferia del capitalismo el interlocutor de las empresas de acción internacional tiende a ser el estado controlado por dicho grupo, lo que implica una diferencia considerable del estado antiguo controlado por las burguesías vinculadas a la exportación de productos primarios. Sería erróneo suponer que la naturaleza del estado se esté modificando porque los militares hayan asumido el poder. La presencia de militares en los puestos más altos del comando político no es una invención de la generación actual, por lo menos en América Latina. Ocurre, sin embargo, que esas modificaciones de las funciones del estado están dando un nuevo sentido a la presencia militar en el control del sistema político.

\section{VISIÓN GLOBAL DEL SISTEMA EN LA ETAPA AGTUAL}

Observado en su conjunto, el rasgo estructural más significativo del sistema capitalista parece ser la discontinuidad centro-periferia. Toda tentativa de explicación de su dinámica actual debe partir de esa premisa, tanto más cuanto que las disparidades entre el centro y la periferia tiende a acentuarse. Como señalamos, el crecimiento en el centro se hace con difusión social de los frutos de los incrementos de productividad y en la periferia con la concentración de los mismos. Por otro lado, como la periferia paga al centro por la técnica que utiliza y como parte del excedente generado en la periferia es apropiado por empresas del centro, existe un flujo permanente de recursos desde la periferia al centro, lo que significa que en condiciones normales el ingreso tiende a concentrarse en beneficio del centro. En realidad, se observa un doble proceso de 
concentración del ingreso: en el conjunto del sistema en beneficio de los países céntricos, y dentro de cada país periférico en beneficio de la minoría que imita el estilo de vida generado en el centro. Cuando se acelera el crecimiento en el centro (lo que implica intensificar el flujo de innovaciones a nivel de los bienes de consumo), la repercusión en la periferia tiende a asumir dos formas: mayor concentración del ingreso y aumento relativo de las inversiones improductivas.

Estimaciones aproximadas, de que disponemos actualmente, indican que la tasa promedio de crecimiento anual (de la productividad promedio o del ingreso por habitante) correspondiente al periodo 1948-1970, fue de $3,5 \%$ en el centro y de $2,5 \%$ en la periferia. En 1970 el ingreso promedio en el centro era algo más de 10 veces el ingreso promedio en la periferia; lo que actualmente se agrega en el transcurso de un año al consumo del ciudadano del centro, es 14 veces más de lo que es agregado al consumo del hombre de la periferia ${ }^{11}$. En 1970 , la población céntrica era del orden de $800 \mathrm{mi}$ llones de habitantes, y la de la periferia de 1.700 millones; además, dada la diferencia de tasas de crecimiento demográfico, en ese mismo año la población céntrica aumentó en algo menos de 8 millones y la periférica en más de 40 millones.

La segunda característica notoria del capitalismo contemporáneo es la tendencia a la integración de las economías céntricas. Este proceso responde, en gran parte, a la aceleración del crecimiento; en efecto, la tasa de crecimiento del último cuarto de siglo fue dos veces mayor que las tasas de crecimiento observadas en cualquier período de extensión similar en el último siglo. Como la aceleración del crecimiento en el centro acentúa las tendencias estructurales ya descritas -ampliación de la brecha entre el centro y la periferia y concentración del ingreso dentro de cada país en esta última- cabe admitir que la premisa fundamental que hay que tener presente para comprender la dinámica actual del conjunto del sistema es este proceso de integración, el que presupone la existencia de una superestructura política que crea las condiciones para que las grandes empresas de acción internacional disfruten de una autonomía considerable. Esta superestructura política, como ya señalamos, fue una consecuencia del segundo conflicto mundial del que resultó la unificación de los sistemas de defensa de los países capitalistas bajo la tutela de los Estados Unidos ${ }^{12}$. Así, una mutación en el plano político

${ }^{11}$ Véase Estudio Económico de América Latina, cit., loc. cit. y' comunicado de prensa del Banco Mundial, No 38, de septiembre de 1971.

${ }^{12}$ Esa unidad del sistema de defensa no significa que todas las áreas comprendidas en el sistema gocen de la misma protección. A partir de la adopción por la OTAN de la llamada estrategia flexible a comienzo de los años 60, el territorio 
ocurrida hace tres decenios, abrió paso a toda una reestructuración en el plano económico, cuyo vasto alcance solamente ahora percibimos con claridad. De la mutación política surgió la ideología de la interdependencia, de la solidaridad con los ex enemigos, de la liquidación del viejo colonialismo, de la igualdad de oportunidades para todas las empresas de países grandes y pequeños, del acceso de todos los pueblos (céntricos) a los altos patrones de consumo que el capitalismo industrial había popularizado en Ios Estados Unidos. La institucionalización de esa superestructura política continúa en estado embrionario, pese a que la creación de instancias regionales, sobre todo en Europa, haya permitido ciertos progresos en el sentido de reducir el grado de arbitrio del poder político nacional en el campo económico.

Que la institucionalización de la superestructura política haya permanecido como un proceso abierto, es un hecho importante por cuanto las tensiones generadas por la aceleración de la acumulación parecen entrar actualmente en una fase crítica. Puede parecer sorprendente, pero la verdad es que las mayores dificultades para avanzar en este terreno surgen de parte de los Estados Unidos. Como ya observamos la aceleración del crecimiento en ese país asumió sobre todo la forma de implantación en el exterior de filiales de sus grandes empresas. Ahora bien, la internacionalización de una empresa engendra la creación de un flujo de recursos descle las filiales hacia la matriz. Cuando las filiales están situadas en los países subdesarrollados, las necesidades de equiparlas y abastecerlas de insumos que incorporan alta tecnologia permite, particularmente si el sistema está en expansión, crear un flujo inverso de exportaciones norteamericanas. La solución es más difícil cuando la implantación de filiales se realiza en los países céntricos. En efecto, la evolución de la economía norteamericana en los dos últimos decenios presenta una tendencia al crecimiento más que proporcional de las importaciones, lo que torna aún más difícil, que en los demás países céntricos alcanzar el objetivo del plen:o empleo. A primera vista, el problema puede parecer simple consecuencia de la "sobrevalorización del dólar". Pero si se tiene presente que el sector de la economía norteamericana en

cle los Estados Unidos fue colocado explícitamente en situación privilegiada, pues ningún ataque parcial implica una respuesta global. La gran victoria francesa, bajo De Gaulle, fue conseguir colocar al territorio francés, para fines prácticos de defensa, en situación similar al territorio norteameriçano. Por cjemplo, un conflicto parcial podría llevar a la destrucción de Alemania, o de España, pero no a la de Francia, siempre que el poder atómico de ésta, cuyo comanclo es autónomo, sea convincente. Con todo, este poder es estrictamente local. Si los Estados Unidos y la Unión Soviética tienen una política planetaria es porque disponen de medios militares y económicos para enfrentar un conflicto localizado en cualquier punto de las fronteras de las respectivas áreas de influencia. 
más rápida expansión son las filiales de sus empresas en el extranjero, y que esas filiales se financian en tres cuartas partes con recursos locales, es natural que ellas generen un flujo creciente de recursos hacia las matrices. Por consiguiente, se creó una tendericia estructural a aumentar las importaciones; y pretender compensarlas en la actualidad con la desvalorización cambiaria (que estimula las exportaciones) significaría aceptar una degradación progresiva de las relaciones de intercambio. El problema se complicó todavía más con el avance de la industrialización en la periferia, ya que dada la considerable diferencia del costo de la mano de obra, muchas empresas (en particular las norteamericanas) procuran reestructurarse aumentando sus actividades productivas en la periferia con miras al mercado de los Estados Unidos. La verdad es que la economía norteamericana tuvo que acomodarse a un nivel de desempleo crónico, clos o tres veces más elevado que el que prevalece en los demás países céntricos. Así surgió una esfera importante de conflictos entre vastos grupos de la población norteamericana y los intereses de las grandes empresas en rápida expansión internacional. Estas últimas están interrelacionadas con el sistema de defensa -Pentágono, GLA, etc. - y son extremadamente influyentes en la rama ejecutiva del gobierno. Los grupos más perjudicados canalizan su descontento a través del Congreso, de la prensa y de la inteligencia. Cuando el Ejecutivo parecía haber consolidado su preeminencia -el episodio del Golfo de Tonkín había demostrado que mediante la manipulación de la información el Ejecutivo podía obtener del Congreso las decisiones que deseaba, y el no cumplimiento por Nixon de los vetos presupuestarios parecía indicar que la propia función legislativa podría ser cercenada ampliamente- la confrontación en torno al caso Watergate y la contundente derrota del partido republicano en las elecciones legislativas de 1974, pusieron en evidencia la profundidad de la crisis institucional existente en los Estados Unidos. Que el ejecutivo se haya apresurado casi al término de la última legislatura a obtener la aprobación de una Ley de comercio que lo autoriza a proseguir el esfuerzo de liberalización externa, indica las aprehensiones e incertidumbres con respecto al futuro, pero también denuncia el propósito de continuar avanzando en el proceso de integración del sistema capitalista, a pesar de las tensiones internas. No se excluye la hipótesis de un retorno parcial al proteccionismo, particularmente si el clesempleo crónico se agrava, pero sería erróneo suponer que un retroceso parcial en los Estados Unidos significaría necesariamente un cambio de rumbo en la evolución del sistema a largo plazo.

En los demás países céntricos el proceso de integración viene contribuyendo a un robustecimiento considerable de las grandes empre- 
Oetso Furtado / Una interpretacion estructuralista de la "crisis" actual del capitalismo

sas locales, cuya expansión en el exterior viene permitiendo economías de escala de las que se beneficia el conjunto de la población. La instalación misma de las filiales norteamericanas está contribuyendo a "sustituir importaciones" o a crear nuevas líneas de exportación. El efecto final ha sido, por lo tanto, inverso al observado en los Estados Unidos, es decir, mayor competitividad y dinamismo en el sector exportador con repercusiones positivas sobre el nivel de empleo. La preocupación por robustecer las grandes empresas con sede en el país y asegurarles condiciones favorables de expansión en el exterior constituye una clara indicación de que el proceso de integración continuará. Ahora bien, a medida que la gran empresa va adquiriendo autonomía, creciendo fuera de las fronteras nacionales y aliándose con otras grandes empresas en joint-ventures en diversos países, sus relaciones con el estado del país de origen van adquiriendo nuevas dimensiones. Es común que el estado tienda a actuar en el plano internacional en función de los intereses de las grandes empresas del país respectivo. En cambio, en política interna el estado tiende a encarnar los intereses de otros grupos sociales. Como ya mencionamos, la inestabilidad que se viene manifestando en la dimensión internacional del sistema -la que está engendrando un margen mayor de desempleo crónico en los países céntricos- tendrá necesariamente repercusiones en el plano político y podría conducir a los estados a asumir responsabilidades más amplias en el plan:o social. En otras palabras, si continúa la tendencia en el sentido de la autonomía de Ias grandes empresas, hay que admitir que el estado asumiría funciones crecientes en el plano social y cultural, preocupándose más de los fines -el estilo de desarrollo, la calidad de la vida, etc. - y menos de los medios - organización de la producción, financiamiento de la acumulación, etc. Si la gran empresa tiende a operar como una institución internacional dentro del sistema capitalista, la defensa del nivel de empleo y la preservación de los intereses sociales y culturales de las actuales sociedades nacionales, tendrán necesariamente que transformarse en la preocupación primordial de los estados. Por lo tanto, cabría esperar que estos sean controlados cada vez más por partidos políticos con vocación social, es decir, que representen efectivamente a la masa de la población trabajadora.

Las relaciones entre los estados céntricos (individual o colectivamente) y la superestructura política de un sistema capitalista cada vez más integrado estarán seguramente influenciadas por la evolución institucional interna de los Estados Unidos. Si se agrava el desempleo en este país y se produce un retorno incluso parcial al proteccionismo es probable que los sectores "internacionalistas" (grandes empresas, Pentágono, etc.) refuercen sus alianzas en el exterior, 
creándose oportunidades para que los demás grandes estados del mundo capitalista amplíen su presencia en las instituciones tutelares. Es a la. luz de estas posibilidades que se deben considerar las perspectivas de la formación de un bloque político en la Europa occidental, a partir de las instituciones surgidas del Tratado de Roma. Excluida la hipótesis de una Europa dotada de un sistema de defensa autónomo con capacidad estratégica mundial -en este camino la unidad de Europa encontraría serios obstáculos no solamente de parte de los Estados Unidos, sino también de la Unión Soviéticahay que reconocer que la presencia internacional de una Europa débilmente unida en el plano político no podría ser muy distinta de la que puede tener una Comunidad Económica Europea razonablemente estructurada. Para que las empresas europeas alcanzaran la dimensión de las norteamericanas sería necesario que hubiese una gran concentración de capital, casi seguramente en beneficio de las empresas alemanas, lo que en la práctica no se haría sin resistencias obvias. Por otro lado, las grandes empresas norteamericanas están ampliamente implantadas en Europa y se beneficiarian tanto o más que las firmas locales en caso de una mayor unificación. En una Europa unida políticamente no sería fácil para Francia conservar el margen de autonomía que hoy posee en el plano de la defensa, y es casi seguro que en la esfera política las relaciones de esa Europa con los Estados Unidos se aproximarían más a la línea alemana actual que a la francesa. La verdad es que la formación de la Comunidad Económica Europea benefició tanto a las grandes empresas con sede en los distintos países que la componen como favoreció la expansión de las grandes empresas norteamericanas en Europa. Por lo tanto, debe ser entendida como un hecho fundamental en el proceso de integración de las economías céntricas, y no como la formación de un sistema económico europeo en contraposición al norteamericano. Una mayor presencia europea en las instituciones tutelares del sistema capitalista no quedaría asegurada por un centro unificado de decisiones políticas en Europa, el cual sería necesariamente frágil. El ejercicio de un poder de iniciativa eficaz, como lo viene haciendo Francia, puede tener un alcance mucho mayor.

LOS PLANOS DE CONDENSACIÓN DEL PODER

Si observamos el cuadro que acabamos de bosquejar percibiremos distintos planos de decisión, o esferas de condensación del poder. En primer lugar, está la superestructura política, poco institucionaliza- 
da, surgida en torno a la tutela norteamericana. La evidencia de que el sistema capitalista tiene fronteras dentro del planeta y de que parte importante de esa frontera en la periferia es fluida, el estatuto político particular de dos grandes naciones industriales (Alemania y Japón) derivado de la forma cómo terminó el último conflicto mundial, y el enorme gasto incurrido por los Estados Unidos en el montaje y renovación permanente del sistema de defensa unificado, son factores que contribuyen a dar solidez y estabilidad relativa a esa superestructura política. Con todo, la necesidad de mantenerla a bajo nivel de institucionalización inclica que la distribución del poder dentro del sistema continúa siendo un proceso abierto. Por ende, los objetivos fundamentales defendidos a nivel de la superestructura no pueden confundirse con los intereses específicos de ningún subconjunto nacional. Sería ingenuo suponer que esa especificidad de la superestructura deriva de un 'equilibrio de poder' entre las principales naciones del mundo capitalista o de una imposición de la voluntad norteamericana. Ella traduce la existencia de una estructura (aún en formación) en la cual el poder es más difuso de lo que era anteriormente. Una de las formas más importantes de manifestación de ese poder son las grandes empresas.

El segundo plano de condensación del poder son los estados céntricos. La situación del estado norteamericano es evidentemente singular debido a sus funciones de gestor principal de las instituciones de tutela, particularmente la custodia de las fronteras del sistema. No nos interesa analizar las disparidades obvias que existen entre los estados céntricos, pero sí destacar lo que ya mencionamos con respecto a las crecientes responsabilidades de esas instituciones en la defensa del bienestar de las poblaciones. La defensa del nivel de empleo interno (amenazado por las ondas de inestabilidad que se generan en la dimensión internacional) y la necesidad de preservar o mejorar la calidad de la vida frente a la acción expoliadora de las grandes empresas tienden a ocupar el primer plano de las inquietudes políticas en las llamadas sociedades postindustriales. Por lo tanto, existen condiciones para un perfeccionamiento de la vida política, con ampliación de la representatividad de los centros de decisión. Ocurre como si la difusión del poder - la transferencia de parte de éste a la superestructura y a las grandes empresas- hubiese aumentado la responsabilidad social del estado, única institución que ejerce un poder legitimo, es decir, un poder que encarna valores explícitos y que es efectivamente delegado por una población.

El tercer plano en que se condensa el poder corresponde a los estados periféricos. Aquí la heterogeneidad tanto económica como social, mucho mayor de la que se observa en el centro del sistema, responde a una enorme variedad de situaciones. Lo que interesa sub- 
rayar es el surgimiento generalizado del poder tecnoburocrático y la declinación de las burguesías dependientes tradicionales formadas dentro del marco del sistema de división internacional del trabajo. Mientras estas últimas eran estructuralmente solidarias con los centros metropolitanos, el poder tecnoburocrático emerge como un interlocutor que busca maximizar su margen de independencia. Como es natural este poder no se forma en el vacío. Casi siempre surge como prolongación de una forma tradicional de poder - gestores de los intereses de grupos internacionales, perro guardián de una oligarquía nacional, etc.-, amplía sus funciones en épocas de crisis, ejerce un arbitraje cuando surgen nuevos actores en lucha por el poder. Cuando se presentó el problema de negociar con las grandes empresas de acción internacional en torno a la utilización de los recursos autóctonos no renovables, el poder tecnoburocrático halló condiciones para consolidarse rápidamente y asumir el papel de custodio del "interés nacional". La necesidad de descifrar la información manipulada por las grancles empresas valorizó lo técnico y creó nuevas fuentes de prestigio social. En otras partes, las nuevas funciones financieras e industriales del estado conducirían a resultados parecidos. Lo que tiene de común el poder tecnoburocrático periférico es que en todas partes es el interlocutor de las grandes empresas internacionales animado por el propósito de disputarles parte del excedente de que ellas se apropian localmente. Para alcanzar este objetivo, se utiliza instrumentos fiscales, cambiarios, crediticios y comerciales. Últimamente, se viene utilizando el control directo de parte del capital de las filiales locales de las grandes empresas.

El cuarto plano de condensación del poder son las grandes empresas de acción internacional, que son el instrumento principal de acumulación, de innovación técnica y de integración del sistema. En la periferia, la exploración de los recursos no renovables y la industrialización se realizan bajo el control o con amplia participación de esas empresas, lo que les concede un poder considerable para actuar en el centro. La empresa que opera dentro del marco de los oligopolios tiende fundamentalmente a crecer, y como la forma más fácil de crecer es actuar simultáneamente en muchos mercados -una misma innovación puede ser explorada simultáneamente en varios países céntricos y equipos que son obsoletos en un país de remuneraciones elevadas pueden ser trasladados a otro de mano de obra barata- constituye el auténtico motor de la integración del sistema. Así, a medida que avanza la integración aumenta la participación de las grandes empresas de acción internacional en la generación del producto y en la apropiación del excedente. La autonomía efectiva de la gran empresa de acción internacional constituye una modifjcación importante de la estructura del sistema capitalista. Las deci- 
siones económicas dentro del marco de los antiguos sistemas nacionales se coordinaban en función de criterios de complementaridad, de creación de economías externas y de autosuficiencia con respecto al suministro de recursos básicos. Tales criterios no rigen para una empresa que opera internacionalmente. Así se explica el aumento relativo considerable del consumo de petróleo, el abandono de fuentes alternativas de energía y la orientación de la tecnología en el sentido de acelerar el consumo de hidrocarburos. Habiéndose apropiado a bajísimo precio de las reservas cle petróleo situadas en los países periféricos, las grandes empresas trataron de maximizar ventajas a corto plazo sin preocuparse de las consecuencias para los países consumidores y productores. No cabe duda de que el proceso de integración condujo necesariamente a una interdependencia creciente entre países y regiones dentro del sistema capitalista. Sin embargo, no se puede desconocer que la forma de operar de las grandes empresas precipitó este proceso, creando para la mayoría de los países céntricos, en un período relativamente breve, una seria dependencia de la periferia con respecto al abastecimiento de recursos no renovables. Otra consecuencia importante de que haya predominado el criterio de la gran empresa se manifiesta en la ubicación geográfica de las actividades manufactureras. Dentro del marco de una economía nacional céntrica, el costo de la mano de obra y el poder de compra de la población son dos aspectos de un mismo proceso. Como la productividad crece desigualmente entre sectores, si las remuneraciones promedio aumentan con la productividad media (cosa que ocurre en los países céntricos), es porque los precios relativos se modifican de manera de beneficiar a los sectores en que el crecimiento de la productividad es más lento. El marco en que opera una empresa que se expande en el plano internacional es fundamentalmente distinto, pues en este caso no hay relación entre el costo de la mano de obra y el poder de compra de los que van a adquirir el producto. Para la ejecución de tareas idénticas en la industria manufacturera, la mano de obra en Corea del Sur o en Singapur es diez o doce veces más barata que en los Estados Unidos y en México cuatro o cinco veces más barata.

LA AGRAVAGIÓN DE LAS TENSIONES $Y$ LAS NUEVAS RELACIONES GENTRO-PERIFERIA

La creciente dependencia de los países céntricos con respecto a los recursos no renovables provenientes de la periferia constituye un 
hecho fundamental para entender las tensiones actuales del sistema capitalista. Con respecto al petróleo cabe formular dos observaciones. El súbito aumento del consumo en el centro impidió que se formase una interdependencia, es decir, los países productores no alcanzaron a prepararse para absorber la parte del excedente que les corresponde, lo que les confiere mucho mayor libertad de acción, por cuanto en la mayor parte de los casos incluso la suspensión total de las exportaciones durante un periodo relativamente importante no les crearía dificultades insuperables. En este sentido se diferencian de los demás países exportadores de materias primas. Solamente así se explica que se hayan puesto de acuerdo con relativa rapidez para administrar los precios en el mercado internacional. El segundo aspecto que cabe considerar es de naturaleza distinta: se trata de la dependencia de los Estados Unidos (que se configuró a fines de los años sesenta) con respecto al petróleo del Oriente Medio, hecho de innegables proyecciones políticas. La importancia de este hecho se puso de manifiesto en octubre de 1973, cuando el petróle:o del Oriente Medio fue utilizado de forma convincente como arma política contra el gobierno de los Estados Unidos. Hasta entonces se admitía sin discusión que la existencia de reservas estratégicas de materias básicas, sumada a la producción autóctona y a la diversidad de fuentes externas rigurosamente fiables, ponían al gobierno de los Estados Unidos a cubierto de ese tipo de situaciones. Si el gobierno norteamericano pudo, durante muchos años, llevar adelante la guerra de Vietnam sin autorización explícita del Congreso y contra la opinión pública del país, fue porque disponía de un margen considerable de maniobra. A esta gran libertad de acción se debe que las presiones generadas dentro del país no hayan interferido demasiado en la gestión de los órganos tutelares del sistema capitalista. El embargo del petróleo del Oriente Medio vino a demostrar que cierto tipo de acción internacional ya no puede llevarse adelante sin medidas complementarias internas, lo que significa depender de la movilización de otros recursos políticos menos seguros.

La agravación de las tensiones dentro del sistema capitalista, que se viene manifestando desde comienzos del presente decenio, tiene dos causas principales: el retardo en la institucionalización de la superestructura y la modificación de las relaciones de poder entre los estados céntricos y periféricos. La forma de conducir la larga guerra fronteriza del Vietnam y las peculiaridades del prolongado conflicto del Oriente Medio, con respecto a lo cual no es posible en los Estados Unidos aislar los aspectos de política interna de los de política externa, erosionaron el liderazgo norteamericano y retardaron seguramente la institucionalización de la superestructura política. Si a eso se agrega el debilitamiento del poder ejecutivo dentro del gobierno 
de los Estados Unidos frente a las crecientes dificultades de conciliar los intereses de las grandes empresas, empeñadas en la integración del sistema capitalista, con otros intereses autóctonos, se comprencle que el embargo del petróleo haya provocado una serie de trastornos al más alto nivel. Es natural que el gobierno norteamericano haya reaccionado en un amplio frente, procurando por lo menos dar la impresión de que pretenclía re-establecer el slalus quo ante. De ahí la campaña en el senticlo de la "autosuficiencia energética". Ahora bien, una tal autosuficiencia significaría el agotamiento más rápiclo de las fuentes locales y la elevación sustancial del costo efectivo de la energía, lo que reduciría aún más la capacidad competitiva de la economía norteamericana. Es preciso no confundir la elevación del precio del petróleo, como la ocurrida recientemente, con el aumento del costo real de la energía. En el primer caso se trata de la transferencia de recursos de unos agentes a otros; en el segundo, de la baja de la productividad del sistema económico global. Como las grandes empresas norteamericanas están empeñadas en la expansión global del sistema, la segunda solución no puede interesarles. La transferencia del excedente ocasionada por el brusco aumento del precio del petróleo significó, en realidad, un aumento del potencial de inversión en el conjunto del sistema, lo que no puede dejar de beneficiar a las grandes empresas norteamericanas. El desarrollo de otras fuentes de energía es desde luego imperativo, dado que el petróleo es un recruso no renovable; pero esto no impedirá que continúe aumentando la dependencia con respecto a fuentes externas de petróleo. Además, esa tendencia no se limita al caso del petróleo. Según estimaciones del propio gobierno norteamericano, la dependencia de fuentes externas crece inexorablemente con respecto a los "productos estratégicos" de origen mineral. De la lista de 13 productos así clasificados, sólo cuatro (níquel, manganeso, estaño y bauxita) dependían de la importación en más de $50 \%$; desde ahora hasta fines de siglo, ese grado de dependencia se habrá extendido muy probablemente a la totalidad de los 13 productos, siendo que con respecto a siete de ellos se prevé una clependencia de más de $80 \%$.

Excluida la hipótesis de un retorno al status quo ante, surge la necesiclad de reducir la concentración del poder a nivel de la superestructura, con una participación más eficaz de otras grandes nacìones céntricas, lo que exigirá algunos progresos en materia de institucionalización. Esta institucionalización (entendiéndose por tal la creación de mecanismos recolectores y codificadores de información y generadores de decisiones) tiendé a ser tanto más reivindicada en el centro cuanto que en las transferencias de recursos, que están ocurriendo en el plano internacional, agravan las tendencias a la inestabilidad. Dichas transferencias están vinculadas a las modificaciones 
de la relación de poder entre los estados céntricos y los periféricos, reflejo de la importancia creciente en el sistema capitalista de los recursos primarios (no renovables y de mano de obra) de que dispone la periferia.

Las circunstancias que giraron en torno a la brusca elevación del precio del petróleo a fines de 1973, contribuyeron a dramatizar este aspecto del proceso de integración de la economía capitalista. Ahora bien, la aceleración de la acumulación y la preeminencia de las grandes empresas en la toma de decisiones conducirían necesariamente a una utilización creciente de los recursos primarios de la periferia. Destruidos los resquicios del viejo colonialismo y modificada la base social del estado, es natural que surgiesen presiones en el sentido de retener localmente una mayor parte del excedente. El acto del gobierno revolucionario de Venezuela, que en 1946 estableció que la mitad del excedente generado por la economía petrolera pertenecía al estado venezolano, constituye un hito histórico en las relaciones centro-periferia. Como las grandes empresas del sector petrolero administran tradicionalmente los precios en escala internacional (gran parte del crudo se vende a las refinerías de la misma empresa), no les fue difícil asimilar los impuestos a los costos de producción y restablecer el margen de utilidades en detrimento del consumidor final. Así se estableció un entendimiento tácito entre los países productores y las grandes empresas, cuya contabilidad inflada brindaba mayores posibilidades de ganancia. Al sustituirse en la administración de los precios el antiguo cartel de las empresas por un cartel de estados, se pudo provocar una amplia transferencia internacional de recursos en clesmedro de los consumidores. Dicha transferencia asume en buena parte la forma de control de activos financieros por los agentes beneficiarios lo que significa que los recursos reales permanecen en los propios países céntricos. Otra parte asume la forma de incremento del gasto real en el país beneficiario (con elevado contenido de importación), lo que significa que la distribución del ingreso se está modificando efectivamente a nivel internacional. Si esta modificación prosigue por algunos años, se habrán creado las condiciones para que algunos de los países periféricos se incorporen al centro del sistema. Se trata, sin embargo, de una modificación que afecta a una pequeña parte de la población del sistema. Pero, incluso si se deja de lado la situación excepcional de algunos países exportadores de petróleo, hay que reconocer que la tendencia actual apunta hacia una valorización del conjunto de los recursos primarios de la periferia, sobre todo de los no renovables. La defensa de un recurso como la mano de obra -mediante la celebración de acuerdos internacionales entre países periféricos que aseguren un nivel mínimo de remuneraciones (incluidos los 
Oelso Furtada / Una interpretación estructuralista de la "crisis" actual del capitalismo

impuestos locales) para los trabajadores empleados en las industrias de exportación controladas por las grandes empresas- es un objetivo lejano. Pero caben pocas dudas de que es en esa dirección que se perfila la evolución de las relaciones centro-periferia. Como la transferencia de recursos a que nos estamos refiriendo, asume la forma de modificación de las relaciones de interçambio centro-periferia en favor de esta última, el volumen y el valor de las transacciones internacionales tiende necesariamente a aumentar. En la fase de reajuste, durante la cual la tasa de crecimiento de las exportaciones del centro hacia la periferia es mayor que la tasa de crecimiento de las exportaciones de la periferia hacia el centro, la presión inflacionaria en este último tendrá que ser elevạda, según se comprueba actualmente. Es natural que frente a una situación de esta índole los gobiernos de muchos de los países céntricos más afectados por la transferencia de recursios recurran a medidas que acarrean necesariamente la ampliación del margen interno de desempleo. Sin embargo, sería erróneo suponer que efectivamente se trata de una crisis o sea, de un proceso acumulativo de desempleo fuera de control. Lo que no impide que ciertas industrias experimenten mayores dificultades debido a la desaceleración del crecimiento y a la modificación de la composición del gasto. Por ejemplo, tal es el caso de la industria automovilística que sufre en Europa el fuerte impacto de la elevación de los precios relativos del petróleo en un momento en que el mercado regional se aproxima al punto de saturación. Como la expansión cle esas empresas en la periferia -acelerada con la transferencia de recursos- está asumiendo la forma de instalaciones de filiales progresivamente integradas, el crecimiento global de la empresa puede coincidir con la reducción de sus actividades en el país de origen. En todo caso, los efectos de la desaceleración del crecimiento serán menores en los sectores directamente beneficiados por el aumento de las exportaciones hacia la periferia: producción de insumos industriales, equipo, servicios de ingeniería, gestión, etc.

CONVERGENGIA EN LA BÚSQUEDA DE UN NUEVO

PROYEGTO DE GIVILIZACIÓN

La transferencia de recursos que hemos mencionado es sólo un aspecto de un problema más general que es el de la creciente escasez relativa de recursos no renovables y la responsabilidad de las grandes empresas en el uso expoliador de los mismos. En la medida en 
que la orientación general del desarrollo esté definida por las grandes empresas, es natural que el uso de los recursos no renovables se haga en función de un horizonte temporal relativamente estrecho. Por otra parte, el poder de que disponen las empresas en el sistema capitalista es lo bastante grande -generación de ahorro, orientación de la innovación técnica, manipulación de los consumidores- como para que puedan enmarcar la reproducción del sistema económico"ocial de manera de evitar modificaciones significativas en la repartición del ingreso. Por ello resulta que una parte importante del incremento del ingreso debe ser consumida (si se desea evitar problemas de insuficiencia de demanda efectiva) por una minoría reducida de la población, lo que exige un flujo permanente de nuevos productos y modelos, y una rápicla obsolencia de los bienes de consumo. Este estilo de desarrollo se ha caracterizado por un costo creciente en términos de recursos no renovables. Como los nuevos bienes tienden a difundirse, debiclo al conocido efecto de demostración que presta ejemplaridad al comportamiento de los grupos de-más altos ingresos, se crea un proceso inexorable de elevación del coeficiente de desperdicio en términos de recursos no renovables. La toma de conciencia de ese problema viene siendo estimulada por el comportamiento reciente de los países periféricos. El planteamiento del problema de la orientación del desarrollo conducirá con mucha probabilidad en los países céntricos a una confrontación del estado con las grandes empresas. Como la forma más fácil y socialmente más aceptable de reducir el coeficiente de desperdicio consiste en aumentar relativamente las formas colectivas de consumo, o sea, reducir en términos relativos el ingresto disponible para el consumo privado, la tendencia será a planificar la repartición del ingreso y a reducir el poder de las grandes empresas sobre las actividades innovadoras directamente ligadas a la transformación de las normas de consumo. Respecto a la periferia, el poder creciente de las grandes empresas surge como un problema de dimensiones aún mayores. Como ya observamos, la orientación del proceso de industrialización por dichas empresas significa el trasplante de formas de vivir que corresponden a países de mucho más alto nivel de acumulación. Cabe agregar que esos estilos de vida implican un desperdicio considerable de recursos escasos, desperdicio que es ostentado por una minoría privilegiada al lado de la enorme miseria que pesa sobre las grandes masas de la población. Además, debiclo a un efecto perverso, la valorización de los recursos no renovables repercute negativamente en grandes zonas de la periferia, cuya heterogeneidad, como ya dijimos, es considerable. Las tensiones actuales que provocan la transferencia de recursos desde el centro hacia la periferia agravan también las disparidades dentro de esta última. Habría que distinguir 
tres situaciones. Un pequeño grupo de países exportadores de petróleo que, debido a la reducida población, alcanzarán posiblemente el grado de homogeneidad social, el nivel de ingreso y otras características de los países de capitalismo céntrico. El segundo grupo, demográficamente mucho más importante formado pior países exportadores de petróleo $\mathrm{y} / \mathrm{u}$ otros recursos primarios, que se están beneficiando del mejoramiento de las relaciones de intercambio, y que experimentan una elevación de la tasa de crecimiento. Sin embargo, debido a la orientación dada al desarrollo -industrialización bajo el control de filiales de grandes empresas- la elevación de la tasa de crecimiento agrava las desigualdades sociales. Un tercer grupo de países, importadores de petróleo y de otros recursos no renovables, constituye la pieza más frágil de todo el sistema. En estos últimos convergen actualmente las presiones generadas por el deterioro de las relaciones de intercambio y las producidas por la concentración del ingreso inherentes al capitalismo periférico.

Parece indudable que las tendencias estructurales actuales del sistema capitalista conducen a un aumento de las tensiones sociales en la gran mayoría de los países periféricos, sea como consecuencia del deterioro de las relaciones de intercambio (caso del tercer grupo), sea como consecuencia de la mejora de las relaciones de intercambio, mediante la aceleración del crecimiento y la mayor concentración de ingreso (caso del segundo grupo). Debido a la mayor versatiliclad del poder tecnoburocrático, siempre dispuesto a reestructurar sus bases de apoyo, se comprende que estén surgiendo en muchos países movimientos que se proponen como objetivo un vasto programa de reconstrucción social. En todas partes dichos movimientos conducen a modificaciones de fondo en las relaciones con las grandes empresas, ya no sólo en el sentido de apropiarse de la mayor. parte del excedente, sino de reducirles la acción como vectores de los estilos de vida de los países céntricos. Se manifiesta la tendencia a concebir el desarrollo a partir de una identificación de las necesidades fundamentales de la población y de la movilización de ésta para asumir la responsabilidad de muchas obras que la benefician. Así, la actividad económica se subordina explícitamente a un proyecto social. En síntesis, las tensiones estructurales más significativas que se manifiestan tanto en el centro como en la periferia del sistema capitalista parecen favorecer la subordinación de lo estrictamente económico a valores sociales. Sería ingenuo suponer que la época de las disparidades crecientes entre el centro y la periferia y dentro de los países periféricos esté llegando a su fin. Pero, existen. indicios de que se gesta una época de convergencias, a partir de una concepción del desarrollo que implica un nuevo proyecto de civilización. 